\title{
NUEVAS CONCEPCIONES SOBRE LOS DUELOS POR PÉRDIDA DE SERES QUERIDOS
}

\section{New conceptions about mourning for loss of the loved ones}

Laura Yoffe*

\begin{abstract}
Resumen
En las últimas décadas se ha alcanzado un acuerdo razonable entre los investigadores con respecto a conceptos y manifestaciones asociadas al duelo (Stroebe et al., 2007). Son grandes los avances realizados a partir de las concepciones del "trabajo" de duelo (Freud ,1917), las "fases" (Bowlby,1980; Kubler Ross,1984 ) y las "tareas" de duelo (Worden, 1991). Gran cantidad de investigaciones realizadas recientemente reconocen al duelo como un fenómeno complejo que incluye niveles biológicos, psicológicos, sociales y espirituales (Stroebe et al., 2007).

Los nuevos estudios ampliaron y profundizaron la teoría del afrontamiento del estrés presente en situaciones negativas y/o traumáticas (Lazarus \& Folkman, 1984) al investigar los procesos cognitivos, emocionales, sociales y espirituales que utilizan personas de distintas edades, pertenecientes a distintos credos y culturas para enfrentar diversos tipos de pérdidas (Stroebe et al., 2007; Folkman, 2007; Rosemblatt, 2007).

Uno de los hallazgos principales de mi investigación de Tesis Doctoral realizada con sujetos de distintos credos, es el referido al tipo de muerte y duelo como factores que condicionan el afrontamiento de la pérdida (Stroebe et al., 2011); ya que es el efecto de la anticipación el que imprime diferencias en el afrontamiento del duelo en función del tipo de muerte, en tanto anticipada o inesperada, repentina y/o trágica (Yoffe,2012a).
\end{abstract}

Palabras clave: Duelo anticipado, pérdida inesperada, afrontamiento.

\begin{abstract}
In recent decades it has reached a reasonable agreement among researchers regarding concepts and manifestations associated with mourning (Stroebe et al., 2007). The progress are great from the conceptions of mourning "work" (Freud, 1917), the "phases" (Bowlby, 1980; Kubler Ross, 1984) and the "tasks" of mourning (Worden, 1991). A lot of recent research recognize the mourning as a complex phenomenon that includes biological, psychological, social and spiritual levels (Stroebe et al., 2007).

New studies broadened and deepened the theory of stress confrontation present in negative and / or traumatic situations (Lazarus \& Folkman, 1984) to investigate the cognitive, emotional, social and spiritual process that people of different ages use, belonging to different creeds and cultures to confront various types of losses (Stroebe et al., 2007; Folkman, 2007; Rosemblatt, 2007).

One of the main findings of my doctoral thesis research performed with people of different creeds, is referred to the type of death and mourning as factors that influence the confront of the loss (Stroebe et al., 2011), as is the effect of the anticipation that prints the differences in the confront of mourning depending on the type of death, as anticipated or unexpected, sudden and / or tragic (Yoffe, 2012a).
\end{abstract}

Keywords: Anticipatory mourning, unexpected loss, confront.

\footnotetext{
* Psicoterapeuta Corporal en Biosintesis, Miembro de la International Foundation for Biosynthesis (IFB). laurayoffe@hotmail.com
} 


\section{NUEVAS CONCEPCIONES SOBRE EL DUELO}

La pérdida de un "ser querido se encuentra entre los sucesos vitales negativos, criticos y/o traumáticos que pueden afectar la salud fisica, emocional y mental de las personas que están atravesando un duelo. Diversidad de estudios dan cuenta de los efectos negativos que las pérdidas pueden tener sobre la salud, sobre el aumento de las tasas de mortalidad, morbilidad, suicidio y de trastornos emocionales, psicosomáticos y mentales de los deudos (Lundin,1984; Parkes,1972; Stroebe \& Stroebe,1987/1994) .

La revisión bibliográfica de las investigaciones sobre el duelo indica que no existe una sola disciplina o un paradigma único que sea dominante. Entre las teorías que priman en la actualidad podemos destacar las siguientes:

El psicoanálisis ha jugado un rol central en el desarrollo de la teoría moderna sobre el duelo (Parkes,1972; Rando,1991), basada originariamente en la teoría freudiana, en particular, en el texto Duelo y Melancolía (Freud,1917), donde se diferencia la melancolía del duelo y se postula a este último como un proceso intrapsíquico y privado. A partir del desarrollo del psicoanálisis, el interés se centró en el "trabajo de duelo" orientado a ayudar al paciente a disolver el vínculo de apego al difunto, para poder moverse hacia una salida normal del duelo (Bowlby, 1980; Lindemann, 1994; Parkes, 1998).

Para Bowlby (1980), la relación de apego característica en animales como en seres humanos es necesaria para el crecimiento del ser, ya que al nacer indefenso, éste mantiene un contacto con su cuidador para evitar posibles daños. El otro es percibido como fuente de satisfacción alimentaria, psicológica y social. Si el ser humano o el animal se sintieran amenazados por la posibilidad de perder a su cuidador, surgirían fuertes reacciones emocionales expresadas a través de conductas de ansiedad, angustia o estrés que podrían llevar a la disminución o alteración del funcionamiento del sistema inmunológico $\mathrm{y}$, consecuentemente, al desarrollo de distintos tipos de enfermedades. La expresión emocional en el duelo no es una simple respuesta privada a la pérdida, sino un esfuerzo de parte del deudo para reestablecer la conexión con el objeto perdido, y obtener así consuelo y alivio de los demás seres vivos.
Hagman (1995) considera que el modelo psicoanalítico freudiano dejó de lado la importancia del rol que juegan los "otros", como también los factores sociales que pueden facilitar y/o impedir la recuperación de quienes han sufrido la pérdida de un ser querido. El autor concibe al duelo como un proceso intersubjetivo en el cual será necesario transformar y reestructurar el apego hacia la persona fallecida. En su abordaje relacional, la afectividad buscaría preservar o restaurar la conexión interpersonal con los otros, ya que muchas de las problemáticas que pueden surgir suelen deberse al fracaso de los demás para comprometerse con los deudos.

Rosemblatt, Walsh y Jackson (1976), revisaron una muestra estratificada del duelo en 78 culturas estudiadas por antropólogos, y demostraron la gran variación y las diferencias del duelo existentes entre distintas culturas. Los autores refieren la gran diversidad en torno a las concepciones sobre la muerte, a la posibilidad de reunión posterior con el difunto, al sentido y la expresión o la represión de las emociones a posteriori del fallecimiento del familiar y a las creencias relacionadas con la muerte, tal como son concebidas en las diferentes culturas. La perspectiva social construccionista sobre el duelo de dichos autores considera que los términos: muerte, aflicción, sentimiento, cultura, sociedad, religión, género, evidencia etnográfica son construídos socialmente; y que la muerte es una situación difícil a lo largo de todas las culturas: aunque la experiencia de duelo pueda ser universal, las respuestas a las pérdidas tienen grandes variaciones por ser influenciadas por factores tales como: las relaciones y expectativas familiares, las redes sociales, la religión y la cultura.

Desde la perspectiva de la psicología social transcultural, Parkes (1998) afirma que quienes han sufrido la muerte de un ser querido tienen algo en común, por lo que el duelo tiene un sentido universal que trasciende la cultura. Quienes están en una situación de migración de una cultura a otra, podrán encontrarse sin un espacio social para expresar su dolor y, al hacerlo (según el modo de la cultura de la cual provengan), podrán sentir que no encajan con el grupo social del país o la región a la cual se han trasladado. Es posible que sientan inadecuación frente a los demás, los que -al no ser del mismo contexto sociocultural 
que los deudos- podrían confundirse y/o inhibirse de brindar apoyo social al no comprender sus costumbres ni sus prácticas religiosas espirituales diferentes. Algunas familias podrán aceptar los sentimientos de los deudos y darles sostén para que puedan expresar sus emociones. Otros, en cambio, les requirirán que "estén a la altura de los acontecimientos" y se muestren fuertes. En algunas familias se discutirá lo que está bien sentir, y lo que no es apropiado expresar en el duelo. Estas actitudes podrían invalidar a quienes sufrieron pérdidas, al dejarlos con la sensación de "estar en falta" por lo que sienten o por cómo lo sienten. Mientras algunos miembros de la familia recibirán apoyo para la expresión de sus emociones, otros podrán sentir todo lo contrario (Parkes,1998).

Rosemblatt (1997), resalta la importancia de brindar apoyo social que aporte distracción al deudo, ayudándolo a salir de las profundidades de su depresión, haciéndolo sentir sentimientos positivos que provienen de recibir ayuda de los otros. Para Fernández, Ubillos, Zubieta y Páez (2001), el apoyo social implica la existencia o disponibilidad de personas en quienes se puede confiar, y promueve la capacidad de sobreponerse a frustraciones y duros desafíos. La presencia de una red social provee a la persona de elementos sociopsicológicos que ayudan a mantener su salud mental y emocional. Rosemblatt (1997), pone de relieve al apoyo religioso de pares religiosos y/o espirituales como fuente de alivio, confort y consuelo que permite que quienes han perdido a un ser querido se sientan apreciados y valorados a través de manifestaciones de cariño y respeto hacia el ser querido fallecido, y de la expresión de condolencias hacia sus deudos. Destaca el apoyo que la congregación de pares religiosos brinda a sus miembros en momentos de crisis vitales o de situaciones de estrés como las pérdidas por muerte de seres queridos.

Las nuevas investigaciones sobre el duelo señalan los riesgos de morbilidad y mortalidad que pueden surgir a posteriori de la pérdida de un ser querido. A partir de su estudio con viudas y viudos, Parkes (1998) afirma que la obligación de sufrir a solas y a escondidas agrava el dolor por la pérdida sufrida, y produce efectos negativos que pueden llevar al aumento de las tasas de mortalidad de viudos y viudas al año de la muerte de su cónyuge. El autor refiere que la tasa de mortalidad presente en pérdidas por viudez es mucho más alta que la de la fracción representativa de la misma edad; y que la "respuesta inmunitaria del cuerpo" se relaciona con las infecciones, el cáncer y enfermedades más serias. Duberstein (2000), enfatiza también la conexión entre el desarrollo de enfermedades y el aumento de las tasas de mortalidad presentes en los deudos, y refiere como necesario considerar la relación entre el duelo, la depresión y las funciones inmunológica y neuroendocrina, ya que durante el duelo suele darse un debilitamiento de las habilidades de los deudos para responder o afrontar las enfermedades. Hall e Irwin (2001), realizaron una revisión sobre el funcionamiento fisiológico en situaciones negativas como el duelo, a partir de la cual describen los cambios presentes en los múltiples sistemas fisiológicos que incluyen el sistema inmunitario, el neuoroendócrino y los factores relacionados con el sueño. Los autores reafirman las relaciones existentes entre el duelo, la depresión y la enfermedad física. También Parkes (1998) destaca que el suicidio, la cirrosis y los ataques cardíacos son las tres causas principales de muerte conectadas al duelo. Jones y Goldblatt (1987), sostienen que los accidentes pueden ser relacionados con el duelo, ya que en las primeras etapas, los deudos suelen tener dificultades de concentración mientras manejan vehículos; algunos consumen demasiado alcohol, lo que podría producir accidentes automovilísticos. Según Goodkin et al., (2007), el efecto de mortalidad en el duelo suele ser mayor en la población de sexo masculino que en la de sexo femenino.

Otras concepciones sobre el duelo ponen el acento en la búsqueda de sentido y propósito a posteriori de la pérdida (Janoff-Bulman,1992; Neimeyer, 2001). Neimeyer (2001) señala la emergencia de un nuevo paradigma que postula la reconstrucción del sentido de la pérdida como respuesta central en el duelo, enfatizando los procesos de búsqueda de atribución de sentidos a los hechos negativos a través de la organización de la experiencia de manera narrativa. En sus estudios, Pennebaker et al.,(1997), señalan que quienes podían expresar sus sentimientos y los hechos relacionados con los sucesos traumáticos que habían padecido, posteriormente, realizaban menos consultas y asistían con menor frecuencia a centros de salud; a diferencia de quienes no lograban expresar sus sentimientos relacionados con las situaciones 
negativas y/o traumáticas sufridas. Según los autores, la inhibición activa de los pensamientos y sentimientos presentes en el duelo o posteriores a un trauma requiere de un trabajo que -a lo largo del tiempo- actuaría como un acumulador de estrés que aumentaría el riesgo de enfermedad y de los problemas relacionados con el estrés. En cambio, la expresión de los propios pensamientos y sentimientos -a través de la escritura terapéutica y/o de la terapia- podría interrumpir esa secuencia al producir efectos terapéuticos positivos.

Lazarus y Folkman (1984), definen el afrontamiento como un conjunto de estrategias cognitivas, conductuales y emocionales constantemente cambiantes que sirven para hacer frente al estrés que una situación puede generar, como también para manejar las demandas específicas externas y/o internas que son evaluadas como excedentes o desbordantes de los recursos del individuo. A partir de allí, Folkman (2007), desarrolla la teoría sobre la cognición y el afrontamiento estrés relacionada con el duelo, que ha tenido gran influencia en las investigaciones recientes, al reconocer el rol de las emociones positivas como respuesta de adaptación positiva al duelo. Esta concepción se contrapone a las teorías de Bowlby (1980 ) y de Parkes y Weiss (1983), que ponen énfasis en las fases que necesitan atravesar los individuos en duelo, y en las tareas de adaptación a la situación de pérdida de un ser querido. En cambio, Folkman (2007), destaca dos estilos de afrontamiento enfocados hacia: a) la resolución de los problemas presentes en el duelo, a través de esfuerzos específicos que desarrollan los deudos para alcanzar sus objetivos más próximos y, b) la apreciación positiva a través de estrategias cognitivas de reencuadre y reatribución de sentidos para mantener la afectividad positiva en el duelo. La autora también incluye las creencias y experiencias religiosas espirituales a través de las cuales, los deudos pueden hallar un sentido espiritual y una afectividad positiva relacionados con la situación negativa que deben afrontar. Los modos de afrontamiento del duelo podrán permitir hallar nuevos sentidos a la pérdida y a la vida, luego del fallecimiento del ser amado. Este enfoque coincide con el de Pargament (1997), quien destaca la multiplicidad de estrategias y estilos de afrontamiento religioso espiritual para hacer frente a situaciones de negativas y estresantes como son las pérdidas de seres queridos.
Stroebe y Schut (2007) desarrollaron un modelo de afrontamiento del duelo como proceso dual donde el deudo puede oscilar en dos direcciones a través de: a) un movimiento de afrontamiento de la pérdida; y b) un movimiento tendiente hacia la recuperación, como modo de adaptación a la muerte del ser querido. Por momentos, el deudo necesitará evitar y negar la pérdida para poder desarrollar nuevos roles, llevar a cabo actividades y realizar cambios distintos al estilo de vida que llevaba con anterioridad al fallecimiento de su familiar. Dado que las personas tienen capacidades y recursos diferentes, sus estilos de afrontamiento "de acercamiento" y de "evitación" podrán diferir y permitirles llevar a cabo movimientos de ida y de vuelta entre ambas estrategias. Por ello, será necesario investigar los estilos de cada sujeto, sus capacidades de afrontamiento y el impacto que la pérdida del ser querido podría provocar sobre la cosmovisión de los deudos.

La frase tareas de duelo fue acuñada por Freud (1917) y retomada posteriormente por Parkes y Weiss (1983) y Worden (1997). Para Worden (1997), el duelo es un proceso, no un estado, por lo cual deja de lado la noción de "fases" del duelo ya que considera que las mismas implican cierta pasividad de parte de los deudos. También plantea como las tareas de duelo a: la aceptación de la realidad de la pérdida, el experimentar la aflicción en el duelo, trabajar las emociones y el dolor para no desarrollar adicciones como modo de bloqueo de los sentimientos y de negación del sufrimiento presente en el duelo; la adaptación al medio sin la presencia del ser querido fallecido, en la cual el deudo deberá desarrollar habilidades nuevas, asumir nuevos roles y buscar nuevos sentidos a la vida; la "relocalización" emocional del ser querido fallecido, encontrándole un lugar apropiado en su vida psicológica, y dejando espacios para los demás seres vivos, desde la intención de moverse hacia adelante al futuro para vivir de manera más eficaz y placentera.

La concepción de Folkman (2007), se contrapone a las teorías de Bowlby (1980), Parkes (1972), y Kübler- Ross (1969), que ponen énfasis en las fases que necesitan atravesar los deudos como en las tareas de adaptación a la pérdida. Barreto y Sáiz (2007) acuerdan con el modelo sobre el trabajo de duelo y plantean la necesidad de que el deudo experimente 
y pueda expresar las emociones negativas durante los primeros meses posteriores a la pérdida, ya que así se reduciría el malestar a largo plazo. La evitación o la minimización de la experiencia y la falta de expresión de las emociones negativas podrían predecir dificultades en la resolución del duelo.

La hipótesis sobre el trabajo de duelo fue considerada de gran importancia como un proceso cognitivo que el deudo debe realizar para confrontar la realidad de la pérdida sufrida, los sucesos relacionados con los momentos previos y posteriores a la muerte del ser querido y los recuerdos en su elaboración del duelo, de modo de poder desapegarse de la figura del ser querido fallecido. En cambio, Bonnano (2007) sostiene que la falta de sentimientos de malestar o de aflicción en el duelo no significa una ausencia de aflicción ni una reacción de duelo postergada, aunque este aspecto haya sido considerado de manera negativa por los autores que sostienen la perspectiva de la teoría del "trabajo de duelo". También Wortman y Silver (2007) señalan que, en ocasiones, la muerte del ser querido conduce a una disminución del malestar en el duelo y por ello, puede que no surja un aumento de emociones negativas en el deudo a posteriori del fallecimiento del ser querido. Los autores consideran que el duelo puede poner fin a una situación estresante en los casos en los que la persona debe cuidar a un familiar enfermo durante mucho tiempo o cuando debe sobrellevar una carga afectiva muy pesada durante dichos cuidados. En este tipo de circunstancias, la muerte podría poner punto final a una situación de sufrimiento por tener que acompañar a quien padece una enfermedad terminal severa o con quien se tuvo una relación abusiva previa.

La perspectiva sociofuncional del duelo y de las emociones de Bonanno (2007), contradice las teorías sobre el "trabajo" de duelo, que ponen énfasis en la disminución del malestar y la aflicción y en la expresión de las emociones negativas en el duelo. Para el autor, la hipótesis sobre la recuperación posterior a la pérdida estaría más relacionada con la activación y la facilitación de las emociones positivas, que con la disminución del malestar que surge como producto del duelo. A partir de allí, plantea que las emociones positivas no sólo no impiden un trabajo adecuado de resolución del duelo, sino que juegan un importante papel en la recuperación del sujeto que ha sufrido la pérdida. Para el autor, el experimentar y expresar emociones negativas muy intensas relacionadas con la pérdida podría predecir el desarrollo de un tipo de duelo más severo, tal como se ha podido observar muchas veces en la práctica clínica.

Keltner y Bonanno (1997), destacan que las emociones positivas han sido asociadas a la mejoría en las relaciones sociales, al evocar respuestas positivas de los demás. Asimismo, actúan como predictores ya que mejoran el funcionamiento del deudo a lo largo del tiempo. A partir de allí, Bonanno (2007) destaca la necesidad de poner mayor atención a la recuperación del deudo, tratando de activar, facilitar y/o maximizar las emociones positivas, en vez de atender sólo a la expresión de las emociones negativas y del malestar presente en el duelo.

Tedeschi y Calhoun (1995), estudian los cambios y procesos de transformación personal positivos que logran realizar los deudos después de haber luchado con situaciones negativas presentes en los duelos. Luego de experimentar situaciones traumáticas, algunas personas logran manejar el impacto emocional, desarrollando a posteriori cambios y modificaciones en sus perspectivas y prioridades de vida y procesos de crecimiento personal a partir del duelo. Las investigaciones sobre este tema indican la existencia de gran variedad de respuestas individuales según sea: el tipo de pérdida, el familiar fallecido, el tipo de vínculo establecido con éste, el momento y la forma de la muerte, la edad del deudo al momento de la muerte del ser querido, el lugar y momento histórico social donde se produce la muerte de éste, etc.

Attig (2007), menciona los "aspectos positivos del duelo" referidos a los procesos de aprendizaje y reconexión con familiares, con viejos y nuevos amigos y/o con la comunidad a través de trabajos comunitarios, servicios de voluntariado y/o de actividades creativas, sociales y recreativas, de reconexión con Dios y/o de reconstrucción del sistema de creencias sobre el universo o sobre sí mismo que llevan a cabo los deudos. De modo similar, Stroebe, Hansson, Stroebe y Schut (2007), aluden a cambios positivos en las relaciones con los otros y a cambios personales relacionados con el propio crecimiento que pueden surgir como 
consecuencia de la pérdida de un ser querido. También Jaramillo (2001), se refiere a los procesos de cambios en la identidad personal que dependen de que el deudo sea capaz de desarrollar una nueva imagen de sí mismo, donde la conexión con la figura de apego fallecida pueda ser vista como algo del pasado, y ya no más del presente. Para la autora, reacomodarse a la pérdida implica poder recordar a la persona como ausente y evocarla con cariño y nostalgia, haber aprendido a vivir a partir de alternativas nuevas que permitan seguir adelante, después de haber organizado un nuevo mundo sin el ser querido fallecido.

Según Neimeyer (2007), la experiencia de duelo puede brindar variadas posibilidades de elección sobre cómo atender el malestar causado por la pérdida y cómo centrarse en la adaptación a la realidad externa, que ha cambiado a partir de la muerte del ser querido. Tarockova (1996), señala que las pérdidas de seres queridos son, entre los sucesos negativos, las situaciones más difíciles de la vida pero, al mismo tiempo, pueden servir como oportunidades para el crecimiento personal y para trascender las pérdidas sufridas. A partir del modo en que los deudos atraviesan el duelo, podrán surgir en estos diversos cambios en el modo de vivir, en sus creencias y en sus comportamientos. Así, el crecimiento personal resultante del proceso de duelo podrá dar frutos tales como: a) el surgimiento de nuevas habilidades de afrontamiento y la aparición de sentimientos de autoconfianza; b) el aumento de la autoestima en mujeres viudas; c) el aumento de sentimientos de madurez, el desarrollo de habilidades nuevas y de sentimientos de haber podido enfrentar de manera positiva la crisis que el duelo implicó; d) la aparición de habilidades que permitan al deudo moverse en forma independiente lo que, en el caso de mujeres viudas, podrá reflejarse en ejemplos tales como el hecho de poder viajar solas, retomar sus estudios universitarios, asumir ser consideradas como personas más fuertes por parte de familiares como de amigos. Para Stroebe y Stroebe (1993), los duelos son situaciones de crisis vitales en las que el sujeto puede salir fortalecido y su salud puede mantenerse y mejorarse, según sean las estrategias de afrontamiento que utilice para enfrentar dicho suceso negativo. El duelo no constituye ninguna enfermedad y su desarrollo permite alcanzar un grado de madurez y un crecimiento personal.
Las investigaciones de Parkes (1998), dan cuenta de las diferencias de género en el duelo. Stroebe y Stroebe (1994), refieren que en los países occidentales los hombres suelen necesitar más ayuda para expresar sus sentimientos cuando están en duelo; mientras que las mujeres suelen tener mayor contacto con sus emociones y con la expresión de las mismas. Los hombres suelen ser más proclives a inhibir o a evitar la aflicción en el duelo; lo que aumenta los riesgos de enfermedad cardíaca. Las mujeres -en cambio- suelen sentir la necesidad de búsqueda de ayuda y sostén, por lo cual, suelen solicitar apoyo y ayuda psicológica o psiquiátrica para sus desórdenes afectivos o cuando sienten que están atravesando un duelo crónico. En casos así, las mujeres suelen pedir y salir a buscar apoyo, mucho más que los hombres. En los estudios de Parkes (1998), con personas que habían enviudado, los hombres eran más proclives a sufrir y morir de un ataque cardíaco al año de la muerte de su esposa. En cambio, Mellstrom et al., (1982), mostraron la relación del aumento de las tasas de suicidio entre las mujeres en la primera semana de duelo.

Para Lund (1989), la edad emerge como determinante de las reacciones de duelo, ya que los adultos mayores son menos proclives a hacer un duelo que las personas de menor edad. La mayoría de las investigaciones sobre pérdidas por muerte de un/a hermano/a se han focalizado en adolescentes entre 14 y 19 años de edad. En dichos estudios se pudo observar que la aflicción en el duelo variaba, y se extendía desde el año y medio hasta los siete años posteriores a la pérdida (Balk,1983).

\section{EL DUELO POR LA PÉRDIDA DE UN SER QUERIDO}

Según Stroebe, et al., (2007), en inglés existen tres términos referidos al duelo: mourning, grief y bereavement. "Bereavement" se refiere a la situación objetiva de pérdida de un ser querido, según el tipo de familiar que ha fallecido. Por su parte, "grief" alude a la experiencia personal de pérdida, que implica las emociones de tristeza y de dolor. "Mourning" es utilizado para nombrar las expresiones o los actos expresivos de aflicción moldeados por cada sociedad y cada grupo cultural. "Bereavement" incluye tanto al duelo como proceso, como a las emociones y 
experiencias personales de la "aflicción" presente en los duelos. Jaramillo (2001), también distingue los términos en inglés bereavement mourning y grief, señalando que en castellano, son sintetizados a través de la palabra "duelo".

Stroebe et al., (2007), distinguen las reacciones que pueden surgir ante la pérdida de un ser querido: a) manifestaciones afectivas de depresión, desesperación, ansiedad, culpa, rabia, hostilidad, falta de deseo y sentimientos de soledad; b) manifestaciones de conducta como agitación, fatiga, llanto, retirada, aislamiento social; c) manifestaciones cognitivas como preocupación con pensamientos sobre la persona fallecida, baja autoestima, autorreproches, sentirse desvalido y/o desesperanzado, sentimientos de irrealidad, problemas de memoria, de atención y/o de concentración; y d) manifestaciones fisiológicas y/o somáticas tales como falta de apetito, perturbaciones del sueño, falta de energía, quejas somáticas, sentirse exhausto, quejas físicas similares a las padecidas por el ser querido en vida, vulnerabilidad y susceptibilidad a enfermedades.

Para Jaramillo (2001), el duelo no constituye ninguna enfermedad y su desarrollo permite alcanzar un grado de madurez y un crecimiento personal. Desde el punto de vista dinámico, el duelo es un proceso activo de adaptación a la pérdida de un ser amado, de un objeto o un hecho significativo, que suele involucrar reacciones de tipo emocional, físico, familiar, conductual, social y espiritual que se presentan como respuesta a dicha pérdida.

\section{ESTUDIOS ACTUALES SOBRE EL DUELO}

En los Estados Unidos, el informe denominado Bereavement: Reactions, Consequences and Care: Osterweis, Solomon y Green (1984, El duelo: reacciones, consecuencias y cuidados) trata de una revisión comprensiva de las investigaciones y estudios dedicados a la temática del duelo. En el Informe de Osterweis, Solomon y Green (1984), los estudios realizados mostraban una mayor presencia de riesgos de mortalidad en las situaciones posteriores a la muerte de un cónyuge, señalando que las mayores tasas de mortalidad se hallaban en la población masculina que atravesaba una situación de duelo.
El Project on Death in America (1981, Proyecto sobre la muerte en América) de los Estados Unidos formó una comisión cuyo objetivo fue desarrollar mayor conocimiento sobre el estado de la investigación acerca de la temática del duelo. De esta manera, buscó proveer una base a partir de la cual se pudieran brindar consejos para fortalecer la investigación en dicha área y facilitar la provisión de cuidados adecuados de alta calidad para personas que atraviesan situaciones de pérdida por muerte de seres queridos.

El Report on Brereavement and Grief Research (2003, Informe sobre duelo) fue el resultado de la tarea realizada. Brinda una actualización y síntesis sobre la base de: a) estudios sobre la muerte y el duelo llevados a cabo con individuos y con miembros de la comunidad; b) factores relacionados con la aflicción en el duelo, la salud, los sistemas sanitarios, y c) el efecto de la muerte en los profesionales de la salud que proveen cuidados dentro de dicha área. Su objetivo fue poner más atención en la educación y entrenamiento de los profesionales de la salud que proveen cuidados a quienes atraviesan situaciones de pérdida por muerte de seres queridos. En este Informe, la mayoría de las investigaciones fueron realizadas con población adulta con edades entre 20 y 50 años, aunque también incluyó estudios con participantes de más de 70 años. Se destacan las importantes investigaciones realizadas por Stroebe, Stroebe y Hanson (1999), y por Stroebe, Hansson, Stroebe y Schut (2001), quienes consideraron las publicaciones publicadas en idioma inglés (desde el año 1985 hasta el 2000).

Son de relevancia los estudios de Campos, Páez et al., (2004) y Campos, Páez et al., (2007) acerca del afrontamiento religioso de pérdidas de seres queridos a través de rituales religiosos colectivos, los cuales significan una importante contribución dentro del área en España. Asimismo, Páez et al., (2007), examinaron los procesos de crecimiento personal e interpersonal que se producen después de vivenciar ciertos hechos negativos y/o traumáticos, a partir de la valoración de los modos a través de los cuales la expresión verbal y el compartir emocional fortalecen a las personas y producen el fortalecimiento de las creencias básicas acerca del mundo y de uno mismo. 


\section{TIPOS DE DUELO}

El proceso de duelo implica un tránsito doloroso que podrá tener una salida saludable o dar como resultado un duelo "complicado" o "patológico". Para Bowlby (1998), un duelo "normal" consiste en que el deudo pueda aceptar la pérdida del ser amado atravesando la crisis vital en la cual dicha situación de pérdida lo situó, saliendo revitalizado de la situación, asumiendo una nueva identidad personal en la que se incluyan aspectos nuevos o renovados del sí mismo. Una pérdida reciente puede activar o reactivar la aflicción por una pérdida sufrida previamente, ya que el dolor por la pérdida anterior puede sentirse de nuevo, o posiblemente por primera vez, sobreviniendo así el dolor por la pérdida previa.

El Report on Brereavement and Grief Research (Informe sobre duelo, 2003) se refiere a los progresos que se han llevado a cabo en cuanto a la distinción entre un duelo "normal" y un duelo "complicado". Dicho Informe destaca los riesgos que implican los duelos "patológicos" y los duelos "traumáticos" debido a que los individuos que atraviesan estos tipos de duelos estarían más expuestos a mayores efectos adversos. También menciona las investigaciones sobre las dificultades que se presentan en las situaciones de pérdida de seres queridos, señalando posibles salidas patológicas del duelo que pueden producir síntomas fisicos, trastornos psicopatológicos, enfermedades psicosomáticas, depresión, muerte, suicidio, abuso de alcohol y/o drogas, conductas antisociales e incluso delictivas.

\section{DUELO ANTICIPADO}

Jaramillo ( 2001) sostiene que todo proceso de duelo anticipado se inicia, no con la muerte del ser querido, sino a partir del diagnóstico de enfermedad fatal de éste, lo que podrá permitir a familiares y amigos prepararse y anticipar la pérdida, viviendo en forma cotidiana las múltiples situaciones negativas que la enfermedad los obligará a afrontar. La anticipación de la muerte posibilitará prepararse para ella y para la despedida del ser querido. En el período que va desde el diagnóstico hasta la muerte, la respuesta personal del enfermo podrá fluctuar desde períodos de negación, en los cuales seguirá viviendo como si no estuviera enfermo o como si no supiese que va a morir. En los momentos en que cede la negación, podrán surgir sentimientos de tristeza, miedo, angustia ante la muerte, diversas preguntas sin respuesta, una revisión de las tareas pendientes junto al dolor de tener que separarse de sus seres queridos.

El ser testigo de la enfermedad de un ser querido, del debilitamiento y del progresivo deterioro de las funciones mentales, físicas y psíquicas de éste podrá hacer surgir en los familiares sentimientos de impotencia ante la imposibilidad de detener el proceso de enfermedad terminal, angustia, dolor, sensación de pérdida y sentimientos de vacío ante las pequeñas muertes que irán presenciando día a día. El duelo anticipado conlleva el tener que hacer varios duelos para ir aceptando las pequeñas muertes cotidianas que culminarán con la muerte biológica total.

La reconciliación con familiares y/o la realización de tareas pendientes antes del fallecimiento facilitarán el "buen morir" del enfermo o del anciano. El acompañamiento de sus familiares en los últimos momentos de vida permitirá anticipar la muerte e integrar gradualmente la proximidad de la pérdida. Prepararse para el momento de la desaparición física de la persona amada posibilitará llevar a cabo un duelo sano. Aunque, esto último dependerá también del tipo de vínculo existente entre quien está próximo a morir y sus familiares, lo cual podrá o no complicar el tránsito y el desarrollo del duelo. La oportunidad de decir adiós es valiosa tanto para el enfermo como para sus familiares, ya que puede aportar un sentimiento de alivio a todos ellos. Aunque se trate de un alivio mezclado con tristeza, este proceso permitirá perdonar y perdonarse fallas y errores, así como manifestar agradecimiento por lo vivido en conjunto. El contacto físico, el abrazo, la caricia y la mirada son interacciones de un profundo valor humano. Los recuerdos alegres, las preguntas sobre aspectos de la vida de cada uno, los comentarios sobre el temor ante el futuro, los momentos de alegría, las risas y algunos modos de distracción permitirán a los deudos y a su familiar enfermo sentir paz y armonía por estar juntos antes del fallecimiento de este último (Jaramillo, 2001)

En todo duelo anticipado se podrá tener en cuenta el sentido espiritual de lo que implica decir adiós, despedirse y soltar al ser querido, desapegándose de 
él y dejándolo ir hacia su muerte. La familia podrá sugerir o plantearle al enfermo si desea conversar con un sacerdote o con un representante de su credo que lo pueda acompañar espiritualmente, que realice prácticas religiosas junto a él y/o por él sin imponerlo; siempre y cuando este ofrecimiento sea congruente con la elección religiosa del paciente. Resulta importante destacar las situaciones en las que los familiares logran controlar algunos aspectos relacionados a la enfermedad y /o la internación del ser amado, a través de lo cual pueden ayudarlo a tener una muerte "digna". Todo ello podrá hacerles sentir alivio por haberlo podido cuidar y acompañarlo emocional, práctica y/o espiritualmente (Yoffe, 2012a).

Folkman (1997) destaca la importancia de atravesar un duelo anticipado en el que la muerte es esperada, ya que tanto el familiar enfermo como quien/ es lo acompañan pueden planear y tomar decisiones de conjunto sobre el tipo de cuidados a brindarle durante el transcurso de la enfermedad, sobre los tratamientos médicos, el lugar y el modo de morir, etc. En sus estudios, la autora halló que quienes habían podido llevar a cabo tareas de cuidado de sus seres queridos enfermos durante un duelo anticipado, se refirieron a los sentimientos positivos surgidos al haber sido capaces de ayudarlos a alcanzar una muerte "digna". Las emociones positivas les habían sido útiles para enfrentar las situaciones de intenso malestar surgidas por llevar a cabo tareas de cuidado y acompañamiento del familiar enfermo moribundo.

Asimismo, Schulz, Boerner y Horowitz (2004), llevaron a cabo una investigación longitudinal sobre los efectos en la salud de los cuidadores de familiares en las últimas etapas de enfermedad terminal. Los autores verificaron que quienes se habían sentido sobrecargados por la situación dolorosa, habían sufrido un aumento de los síntomas de depresión, pérdida de peso y habían recurrido a un mayor uso de medicación antidepresiva. Los sujetos que no habían sentido que las tareas de cuidado del familiar enfermo representaban una carga personal no habían sufrido aumento de los síntomas depresivos ni conductas de riesgo para su salud; y tampoco evidenciaron ningún aumento en el uso de antidepresivos ni sufrieron cambios en su peso corporal. Las mujeres mayores que habían cuidado a su esposo enfermo y que habían sentido que dichas tareas representaban una carga para ellas, se refirieron al alivio experimentado a posteriori del fallecimiento de su marido. En estos casos, la muerte en sí misma no produjo aumento del malestar a posteriori del deceso del ser querido, sino que la misma fue percibida con alivio.

Aunque el nivel de malestar psicológico en el duelo anticipado sea elevado, puede coexistir con estados de ánimo y efectos psicológicos positivos en quienes brindan cuidados a su familiar enfermo durante el proceso de duelo anticipado (Moskowitz, Folkman \& Acre, 2003). Los cuidadores podrán sentir que no pueden controlar la enfermedad del ser querido, pero tendrán la posibilidad hacerse cargo de la situación, controlando las tareas de hablar con los médicos y las enfermeras, llamar a los miembros de la familia y/o clérigos para acompañar al moribundo, escribir obituarios, hacer arreglos sobre el funeral, etc. De este modo, podrán percibir que tienen cierto sentido de control sobre la situación, lo cual es muy diferente a sentirse desvalido por tener que enfrentar situaciones en las cuales no es posible controlar nada de lo relacionado con la enfermedad del ser querido moribundo. Moskowitz, Folkman y Acre (2003) afirman que los cuidadores que logran acompañar a un ser querido de manera exitosa pueden percibir en sí mismos estados y afectos positivos desarrollados a partir del cuidado y acompañamiento del familiar enfermo terminal.

Folkman (2007), señala que los tipos de afrontamiento presentes en los duelos anticipados se relacionan con poder hallar sentidos positivos a través de procesos cognitivos y modalidades de afrontamiento centradas en la resolución de problemas, en el uso de creencias y prácticas religiosas y en modos de infundir un sentido positivo a los hechos de la vida cotidiana. El poder hallar sentidos y significados a las situaciones difíciles de un duelo ayuda al aumento de la afectividad positiva, lo cual facilita los procesos de interpretación de los sucesos negativos, creando estados de mente positiva que pueden reducir los niveles de estrés y el malestar presentes en los deudos. 


\section{DUELOS POR PÉRDIDAS INESPERADAS Y/O REPENTINAS}

Stroebe y Stroebe (1994), distinguen las circunstancias que rodean al duelo en relación al tipo de muerte del ser querido, estableciendo diferencias entre una pérdida inesperada luego de un accidente de auto, y otra ocurrida después de una enfermedad de varios años de duración. Señalan que las pérdidas por muerte súbita e inesperada presentan mayores posibilidades y riesgos de producir efectos negativos en la salud fisica y mental de los deudos que las pérdidas en las cuales la muerte del ser querido puede ser anticipada y los familiares pueden despedirse de éste antes de su deceso.

Según Jaramillo (2001), un tipo de muerte repentina puede actuar como un factor que podría complicar el duelo, ya que para el deudo, si el sujeto que falleció era sano, le podrá resultar más difícil aceptar que quien estaba vivo ayer, hoy esté muerto. La muerte accidental es un tipo de muerte súbita inesperada e imprevisible donde todo aparece como absurdo e ilógico; por ello, presenta las mayores dificultades para los deudos. La primera reacción ante la noticia de la muerte inesperada de un ser querido suele ser la incredulidad, por lo cual, el deudo puede sufrir una especie de bloqueo emocional, una anestesia emotiva que funciona como un mecanismo de defensa cuya función es la de cancelar temporalmente el suceso de la pérdida como forma de poder seguir viviendo. A quien atraviesa un duelo de este tipo le resulta casi incomprensible aceptar que quien falleció, habiendo sido una persona buena, pudo haber tenido una muerte tan injusta a través de un accidente, un homicidio, una catástrofe natural, o incluso después de una enfermedad que pudo haber implicado gran sufrimiento previo. A pesar de que el deudo pueda ser una persona de fe y tenga creencias religiosas o espirituales, lo antedicho podría aumentar el dolor y sus sentimientos negativos, su capacidad de comprensión y de aceptación de la pérdida. De todos modos, si los deudos pueden llevar a cabo rituales que les permitan simbolizar la despedida que no pudo realizarse previamente a la muerte del ser querido, podrían ir aceptando lentamente la dolorosa y trágica pérdida sufrida.

Para Lundin (1984), las muertes inesperadas no dan tiempo para prepararse, por lo que las personas en duelos de este tipo pueden sentir mayor tristeza, auto-reproches y hasta sensaciones de embotamiento, fuertes sentimientos de vacío y de anhelo que podrán ser de mayor intensidad que los de aquellos que logran atravesar procesos de duelos anticipados. Reacciones como las de sentirse "atontado", shoqueado o embotado, asi como la imposibilidad de creer que la muerte sucedió suelen persistir durante mucho tiempo después del momento de la pérdida, y pueden asociarse a una constante sensación de presencia de la persona fallecida. En casos así, los deudos pueden sentirse solos, ansiosos y deprimidos, y dichas reacciones pueden perdurar más allá de los dos años. A veces, podrán permanecer más allá de los cuatro años después de producida la pérdida del ser querido. Parkes (2001) coincide con Lundin (1984), en que el "duelo inesperado" suele ser más doloroso, contener más llanto, más reproches y más sentimientos de extrañar al ser querido y que, al mismo tiempo, suele extenderse durante mucho más tiempo que los duelos donde la muerte es previsible, ya que esto último permite a los deudos hacer un "duelo anticipado". Ante la muerte repentina de un ser querido, los deudos pueden quedar rumiando pensamientos e imágenes relacionadas con el tipo de muerte y/o preocupados con el tema de si su familiar sufrió o no antes de morir. Si la muerte hubiera conllevado sufrimiento y/o hubiera sido presenciada por los deudos, los recuerdos que quedan en ellos suelen ser muy dolorosos. Otras veces, éstos pueden quedar con imágenes vividas de la tragedia que pudieron haber presenciado o que hubieran imaginado, y las mismas pueden reaparecer una y otra vez en su mente.

Las situaciones negativas y trágicas, suelen dejar a los deudos con serias dificultades para el afrontamiento del dolor y de la rabia ante la pérdida del ser querido que falleció en circunstancias consideradas absurdas. Asimismo, los deudos pueden sentir gran dificultad para acomodarse y adaptarse a la vida sin la compañía ni la presencia de quien fuera tan significativo para ellos, todo lo cual podría hacer que su duelo se complique y/ o se prolongue.

\section{DUELO PATOLÓGICO}

Barreto y Sáiz (2007), señalan diferencias entre un "duelo normal" y un "duelo patológico", denominando 
a éste último como un "duelo no normal" debido a la presencia de factores tales como: la falta de aflicción conciente, la euforia que puede manifestarse como modo de negación de la pérdida sufrida o del hecho de que el deudo siga con su vida como solía hacerlo habitualmente, sin haber acusado a la pérdida como un suceso que debería haber afectado toda su vida. Bowlby (1980) plantea la existencia de variedades de duelo patológico que pueden alterar tanto la salud mental como la salud física de las personas en duelo, al hacer que queden afligidas, con dificultades para reestablecer y/o mantener relaciones amorosas, entre otras. Si dichas capacidades se vieran afectadas desde antes de la pérdida, las mismas podrán deteriorarse aún más a partir del duelo.

Jaramillo (2001) señala que las pérdidas de hijos son consideradas como uno de los duelos más profundos y difíciles de resolver en el tiempo, tanto por el dolor que acarrean como por las fuertes reacciones emocionales que dicho suceso negativo despierta y provoca en los progenitores. Si la pérdida fue a través de una muerte súbita e inesperada, o producto de una enfermedad terminal de un niño, el tránsito del duelo suele ser más difícil que el que se suele dar ante otro tipo de muerte. Aunque para la autora, los homicidios, suicidios o accidentes, las pérdidas de varias personas de la misma familia implican un tipo de duelo más complejo. De modo similar son los casos en que los familiares no tienen oportunidad de tomar contacto con el cuerpo del ser amado, ya sea porque éste hubiera sido víctima de una desaparición forzada, hubiera sufrido alguna mutilación o desfiguración debido a una muerte por accidente, suicido u homicidio. Estas pérdidas ocurridas en circunstancias traumáticas suelen tornar al duelo en un proceso más complicado y doloroso para sus familiares.

Bowlby (1980), señala a la ausencia prolongada y conciente de la aflicción en el duelo como un tipo de desórden de duelo. De modo similar, Osterweiss, Solomon y Green (1984), afirman que la ausencia de aflicción, que puede manifestarse como negación o inhibición, no conduce a una adaptación normal en el duelo.

\section{DUELO COMPLICADO}

Schupp (2007), plantea que el "duelo complicado" es una interrupción del proceso normal de duelo que prohíbe un cierre saludable y una curación de la persona afectada por la pérdida del ser querido. A veces, se manifiesta a través de una respuesta o una reacción que se prolonga, se dilata en el tiempo, que puede estar distorsionada o ausente, ser excesiva o no resuelta, o puede no estar relacionada con el "trauma" vivido a partir de la pérdida sufrida. El duelo complicado constituye un síndrome único, como entidad diferente con síntomas distintos a los de la ansiedad y la depresión relacionados con el duelo normal.

Ciertos factores pueden incrementar el riesgo de complicaciones en el duelo: una muerte inesperada y repentina, la muerte como consecuencia de una enfermedad larga, la pérdida de un hijo, la muerte que el deudo percibe que podría haberse evitado, la pérdida de un familiar con quien se tuvo una relación ambivalente previa, pérdidas anteriores, duelos no resueltos, problemas emocionales importantes y/o la carencia o insuficiencia de apoyo social percibido por el deudo (Jaramillo, 2001).

Barreto y Sáiz (2007), establecen diferencias entre un duelo "normal" y un duelo "complicado", refiriéndose a que un duelo normal suele tener una duración limitada en el tiempo, aproximadamente entre uno o dos años. Situaciones como la muerte de un hijo, la pérdida de un hermano en la adolescencia, la muerte del padre o la madre en edad temprana y, la pérdida de la pareja pueden producir complicaciones en el duelo. También, los recuerdos dolorosos causados por un diagnóstico tardío, por un mal control de los síntomas o por relaciones inadecuadas con el personal sanitario dificultan la resolución del duelo. Si después de los seis meses del fallecimiento del ser querido el deudo presentara alguna alteración mental tal como una depresión, trastornos de ansiedad y/o adicciones, se debería explorar la conexión de estos síntomas con la pérdida sufrida, ya que los mismos son indicadores de la necesidad de ayuda profesional. Aunque la delimitación temporal del duelo es importante, también se debe considerar la sintomatología, ya que ésta podría indicar la presencia de un duelo complicado. 
Para Schupp (2007), las personas que atraviesan un tipo de duelo complicado suelen perder la confianza en sí mismos y necesitan aprender a salir de su situación de encierro; para ello, deben contar con algún tipo de acompañamiento de quienes los ayuden a salir del aislamiento social en el que se encuentran. Bowlby (1980), se refiere a casos en los que las personas en duelo, a pocas semanas de haber sufrido la pérdida de un ser querido, consideran inútil la presencia de familiares, amigos u otras personas, ya que puede estar dando cuenta de la presencia de signos de aislamiento de parte del deudo. Lo antedicho puede conducir a complicaciones en el duelo a causa de la falta de búsqueda de apoyo o de aceptación para recibir el apoyo de otros con quienes hablar, compartir y/o expresar sentimientos o preocupaciones sobre la pérdida sufrida. En ocasiones, algunos deudos descalifican cualquier tipo de ayuda que podrían recibir en el período posterior a la muerte de un ser querido que implica un momento de alta vulnerabilidad.

\section{RECUPERACIÓN O RESOLUCIÓN DEL DUELO}

Weiss (1999), señala la existencia de tres procesos en el movimiento hacia la recuperación en el duelo: $1^{\circ}$ ) la aceptación cognitiva; $2^{\circ}$ ) la aceptación emocional; y $3^{\circ}$ ) el cambio en la identidad que se produce a partir del trabajo del duelo.

La aceptación cognitiva es aquella donde el individuo, en camino hacia una buena recuperación, desarrolla una compensación satisfactoria de las causas de la pérdida. La validez objetiva del hecho es de menor importancia que la validez subjetiva, por lo cual, algunos individuos con creencias religiosas podrán decir frases tales como las de "fue una forma del misterio divino", que podrán serles útiles para otorgar sentido a la pérdida. La aceptación emocional implica que el deudo logre neutralizar los recuerdos y las asociaciones para que no lo paralicen en su funcionamiento. Este proceso de neutralización requerirá de un monto variable de tiempo. Se deberá tener en cuenta que el mismo suele reactualizarse en los momentos de aniversarios, cumpleaños, vacaciones, fiestas familiares, navidad y fin de año, en las que los deudos vuelven a constatar que el dolor por la pérdida del ser querido no ha terminado del todo.
Según la hipótesis del "trabajo de duelo", el deudo debe alcanzar un estado de recuperación en el que pueda recordar al ser querido y confrontar los recuerdos de la pérdida sin un dolor emocional intenso (Parkes \& Weiss, 1983; Rando, 1991). Wortman y Silver (1992), señalan que cuando los deudos son capaces de incorporar la situación de pérdida dentro de su cosmovisión del mundo, podrán ver al ser querido fallecido ubicado en un lugar mejor y aceptar que las cosas malas suceden y nada se puede hacer al respecto. Aún se considera que la recuperación es el punto de llegada de un proceso de duelo, y por ello, se suele -por lo general- juzgar y evaluar a las personas en duelo según estén o no tomando demasiado tiempo para alcanzar ese punto.

Para Rando (1984), los conceptos de resolución y recuperación no son aplicables a la mayoría de las pérdidas, ya que implican un proceso de cierre del duelo que no suele suceder de esa manera. Los investigadores y clínicos que trabajan en el área de los duelos han comenzado a pensar sobre el proceso de recuperación de una manera diferente, señalando que los deudos no retornan al estado previo a la pérdida (Stroebe \& Schut, 2007).

\section{FACTORES PROTECTORES Y DE RIESGO EN LA SALIDA DEL DUELO}

Según Stroebe y Schut (2007), existen tres tipos de factores protectores o de riesgo que pueden afectar la salida del duelo: a) los relacionados a situaciones referidas al tipo de muerte (anticipada o repentina); b) factores individuales tales como el género y las características previas a la muerte (la estabilidad emocional, creencias y prácticas religiosas y autoestima del deudo) y; c) factores interpersonales (la disponibilidad de apoyo social y emocional, de la familia y de las amistades). Dichos factores pueden actuar incrementando el riesgo cuando la muerte es repentina o cuando hay falta de apoyo social o emocional hacia los deudos-; o jugando un rol protector a través del apoyo social y emocional que brindan familiares, amigos y la comunidad a los deudos.

Según Moskowitz, Acree y Folkman (2003), en algunos deudos el sentimiento de malestar disminuye en momentos muy tempranos del duelo, mientras 
que en otros esto sucede en forma muy tardía; otras personas tienen patrones muy erráticos, ya que se observan aumentos y disminuciones del malestar y de los estados depresivos. Los autores advierten acerca de la necesidad de incluir indicadores positivos sobre la adaptación y la recuperación y los demás procesos que funcionan como indicadores positivos de la salida del duelo. Dado que los deudos tienen capacidades y recursos personales diferentes, sus estilos de afrontamiento "de acercamiento" y de "evitación", les permitirán llevar a cabo movimientos de ida y de vuelta entre ambas estrategias. Por ello, será necesario investigar los estilos de cada sujeto, así como las capacidades de afrontamiento y el impacto que la pérdida del ser querido puede provocar sobre la cosmovisión de los deudos (Stroebe \& Schut, 2007).

\section{DUELO Y TIPO DE VÍNCULO Pérdida de los progenitores}

Si la muerte del progenitor sucede cuando el hijo está cerca de los veinte o treinta años, coincidirá con la etapa en la que éste último está en la lucha por separarse de sus padres, en que sus esfuerzos vitales están dirigidos hacia la construcción de un hogar y una familia propia, y hacia la búsqueda de cierta estabilidad laboral y económica. Pero, si la muerte sucede cuando el hijo está alrededor de los cincuenta años, la misma coincidirá con un momento de mayor estabilidad, ya que se supone que éste ya ha podido consumar las tareas anteriormente señaladas (Jaramillo, 2001).

Jaramillo (2001), señala que ante la muerte de ambos padres, pueden darse diversas situaciones en el adulto: a) el sentimiento de "orfandad", como sensación de que ya no será más un hijo para nadie; b) la tarea de deshacer la casa de los padres como el "refugio real o simbólico del que se era parte"; y c) el proceso de reorganización de la relación entre los hermanos, sin la presencia de los padres. La gravedad de este tipo de duelo dependerá de factores tales como: a) quién era para cada uno el progenitor que murió; b) el rol que éste desempeñó en la vida del deudo; c) los espacios que ocupaba en el mundo interno del adulto, la forma y el momento del ciclo vital en el que murió; d) los recursos internos del deudo, que le permitirán o no afrontar la pérdida de su familiar y e) la disponibilidad de redes de apoyo familiar y social. También Levy (1999), se refiere el sentimiento de "orfandad" que siente el adulto en el momento en que se queda solo sin sus padres. Si los hijos tuvieron una relación tormentosa con los padres, la muerte de éstos podría poner fin a los problemas y conflictos previos. En algunos duelos puede haber situaciones conflictivas preexistentes y/o conflictos de difícil resolución frente a temas de herencias, mudanzas, arreglos domésticos en el hogar familiar, sobre qué hacer con la ropa y las pertenencias del progenitor fallecido y con los objetos de quien aún está vivo, o bien, con las pertenencias de ambos. Los factores antedichos podrán facilitar o dificultar la relación entre los hermanos y/o con el progenitor vivo. En ocasiones, el tener que resolver factores prácticos podrá servir como motivo para rencillas mayores; en cambio para otros, el tener que resolver factores prácticos y materiales podrá servir de nexo para unir más a los hermanos en la nueva tarea de reorganización familiar. Cuando las familias presentan disfunciones y fracturas previas a la pérdida del ser querido, a posteriori de la muerte de éste podrán romperse los lazos, ya que las situaciones críticas suelen hacer aflorar diversidad de emociones negativas intensas (Jaramillo, 2001).

\section{PÉRDIDA DE UN HERMANO/A}

Parkes y Markus (1998), plantean que existe menor cantidad de estudios desarrollados sobre la pérdida de hermanos que sobre la pérdida de padres. La mayoría de las investigaciones sobre pérdidas por muerte de un hermano o hermana se han focalizado en adolescentes que van entre los 14 a los 19 años de edad. En dichos estudios, se pudo observar que la aflicción en el duelo variaba y se extendía desde el año y medio hasta los siete años posteriores a la muerte del ser querido fallecido (Balk, 1983).

La aflicción ante la pérdida de un hermano depende de la edad y del momento de desarrollo de los hermanos que sobreviven a éste. Los niños entre 5 y 11 años pueden comprender los cambios físicos que la muerte acarrea, y podrán percibirlos por si mismos. En muchos casos, los adultos en duelo por la muerte de un hijo suelen encontrarse en situaciones muy difíciles como para poder ayudar a los otros hijos vivos al estar muy inmersos en su propio duelo, 
y sus hijos pequeños o jóvenes podrán verlos muy conmocionados por tal situación negativa. Muchas veces, los padres considerarán, que -como modo de protección- es mejor que los pequeños no participen en las ceremonias funerarias. Si el hijo sobreviviente fue preparado por sus padres para la muerte de su hermano/a y participó en rituales comunitarios, la salida de su duelo será más favorable que en los casos en que no lo hubiera hecho.

Martinson y Campos (1991), desarrollaron investigaciones con adolescentes que habían sufrido pérdidas y habían desarrollado enfermedades como cáncer, señalando que la aflicción ante la pérdida de un/a hermano/a depende de la edad y del momento de desarrollo de los hermanos que sobreviven al fallecido. Plantean que si la pérdida de un hermano es compartida con otros y la familia brinda apoyo al hijo que queda vivo, la salida del duelo será más positiva. Stylianos y Vachon (1993), también destacan las consecuencias favorables del apoyo social en este tipo de duelo.

\section{PÉRDIDA DEL CÓNYUGE}

La muerte de un esposo o esposa, o de una pareja, como la muerte de un hijo, constituyen las experiencias más dolorosas y amenazantes para la estabilidad emocional de los individuos. Cuando una persona enviuda, no sólo pierde a su ser querido, sino que también debe enfrentar la pérdida de la seguridad económica, la falta del par y compañero sexual, la pérdida de su identidad basada en el estar "casado", la sensación y la expectativa de compañía en la vejez, la pérdida de proyectos en común y el acompañamiento en las actividades cotidianas y hogareñas, entre otros. El deudo deberá reorganizar toda su vida y es posible que sienta fuertes sensaciones de ansiedad relacionadas con el miedo de no poder seguir adelante sin el ser amado; sentimientos de vacío y soledad, falta de proyectos y de sentido de su vida y de la vida en sí misma. En presencia de hijos, el viudo o la viuda deberán redefinir su identidad y cumplir además con roles, funciones y responsabilidades que llevaba a cabo quien falleció.

La viudez en la edad madura plantea problemas diferentes, ya que luego de treinta o más años de convivencia, la persona construyó su identidad como la mitad de un todo: los amigos son comunes, los hijos se han ido o están por irse de la casa, y la vida en adelante promete la plenitud y el disfrute que antes no se tuvo, ya que la pareja estuvo inmersa en tareas de crianza, de educación de los hijos y en el logro de una estabilidad económica (Jaramillo, 2001). Las personas que han enviudado suelen sentir dificultades para vivir sin el otro, desconfían de sus capacidades para adaptarse a una vida sin quien fuera su compañero o compañera. El haber perdido a quien fuera su pilar y apoyo principal, en el cual se sustentaba su bienestar, puede hacerlos sentir que nunca más volverán a ser felices (Barreto y Sáiz, 2007).

La pérdida del cónyuge crea gran cantidad de discrepancias entre el mundo interno y externo de quien ha enviudado. Durante un período largo, las viudas suelen presentar dificultades para descubrir qué cambios son necesarios en su vida y cuál es su punto de vista sobre sí mismas; pero, a medida que se van moviendo en la nueva realidad, es común verlas planteándose si el modo de resolver los problemas es igual al que usaban sus maridos; $y$ hablar refiriéndose a un "nosotros". A medida que el tiempo pasa, las viudas buscan nuevos modos de resolver los problemas, pasando de una "vieja identidad" basada en la identificación con el marido, al reemplazo por una nueva identidad basada en el "yo". La sexualidad y las necesidades afectivas del viudo o la viuda son temas que suelen dejarse de lado en las investigaciones, aunque existe gran diversidad de patrones individuales para el manejo de tales necesidades: algunos pueden sentir sus necesidades sexuales en forma muy intensa al comienzo del duelo, mientras que otros reprimen sus deseos sexuales por lealtad hacia la persona fallecida, $\mathrm{y}$ algunos pueden renunciar en forma permanente, decretando su muerte sexual a partir de la pérdida del compañero o la compañera. Puede ser que con el paso del tiempo surjan nuevamente necesidades sexuales, deseos de intimidad y de contacto, necesidad de abrazos y caricias que haga que los deudos salgan a buscar una nueva relación de pareja. Esto varía según la personalidad y el grado de madurez que el viudo o la viuda tengan a partir de su recuperación en el proceso de duelo (Jaramillo, 2001).

La pérdida por viudez suele ser una situación de crisis que está asociada a una reacción severa 
de duelo y a una reacción conocida como "trauma psicológico". El tener que enfrentar un accidente y la muerte repentina del cónyuge desafía las creencias que el deudo tenía sobre la vida y la muerte, así como las ilusiones, expectativas y los proyectos en relación al vínculo matrimonial y al deseo de pasar la vejez junto al ser querido, sin haber tenido en cuenta el límite del tiempo impuesto por la muerte abrupta. El 95\% de los participantes del estudio de Glick, Weiss y Parkes (1974), destacó que sus creencias religiosas fueron la mayor fuente de alivio ante la pérdida sufrida.

\section{PÉRDIDAS ANTICIPADAS, INESPERADAS, REPENTINAS Y MÚLTIPLES}

En mi investigación de Tesis Doctoral sobre

"La influencia de las creencias y prácticas religiosas espirituales en el afrontamiento de la pérdida por muerte de un ser querido" (2012), llevada a cabo a través de entrevistas en profundidad con nueve sujetos adultos mayores de 40 años, contó con siete participantes religiosos pertenecientes a los credos católico romano, protestante metodista, judío y budista tibetano; y con dos sujetos no religiosos. En las entrevistas se tuvieron en cuenta los siguientes factores: la edad, la enfermedad y/o deterioro previo y el tipo de muerte del familiar, la edad del deudo, la posibilidad de atravesar un duelo anticipado, la duración de tal proceso, el tipo de pérdida: anticipada, repentina, inesperada y/o trágica, la presencia de situaciones negativas en el duelo, el apoyo social y/o religioso espiritual percibido y recibido por los deudos en los rituales funerarios y a posteriori de la pérdida.

Uno de los hallazgos principales de dicho estudio se refiere al tipo de duelo y pérdida del ser querido, ya que en la misma se observaron diferencias en el afrontamiento de los duelos en función de los distintos tipos de muerte: anticipada, inesperada, repentina y/ o trágica. Seis de los nueve participantes sufrieron la pérdida de uno de sus progenitores; en un solo caso se constató la pérdida de una hermana menor, seis meses después de la pérdida de la madre de ambas; en otro, se corroboró una pérdida trágica por viudez después de un buen matrimonio de treinta años. Dos participantes religiosas enfrentaron procesos de duelos múltiples por la pérdida de otro familiar y de una amiga de la infancia a posteriori de la muerte del ser querido. Mi estudio no incluyó pérdidas por muerte de un hijo/a, ni pérdidas a causa de suicidio, catástrofe natural o social u homicidio.

De los nueve sujetos estudiados, cuatro religiosos (mujer y hombre católicos, mujer metodista y hombre budista tibetano) y dos no religiosos (mujer atea y hombre agnóstico), llevaron a cabo procesos de duelo anticipado de una duración variable entre 1 a 6 meses y de 3 a 5 años. Los familiares ancianos y/o enfermos habían estado internados en un hospital o en un instituto geriátrico donde fallecieron. A diferencia de ellos, los participantes judíos afrontaron la muerte de sus padres ancianos que habían estado enfermos previamente durante muchos años, y fallecieron en forma repentina de un ataque cardíaco en el hogar. La mujer budista fue la única que enfrentó la pérdida inesperada y trágica de su marido, fallecido de un paro cardíaco en un sanatorio, poco después de sufrir un accidente en la vía pública.

\section{AFRONTAMIENTO DEL DUELO ANTICIPADO}

En las entrevistas realizadas, el hombre católico relató que pudo acompañar a su padre durante el mes en que éste estuvo hospitalizado. Dado que su familiar sufría de enfisema pulmonar y había sido internado en varias ocasiones, el participante pudo prepararse para su muerte durante varios años. Acerca de ello, manifestó: "Había vivido siempre con la posibilidad en la mente de que algún día iba a sonar el teléfono y me iban a decir 'papá se fue'. Por eso, fue muy importante poder estar con mi padre y acompañarlo en esos momentos. Estar ahí, acompañarlo con mi presencia y mis prácticas religiosas fue una bendición.”

La mujer católica atravesó el duelo anticipado de su única hermana menor fallecida en el hospital a causa de un cáncer de mama por metástasis generalizada. $\mathrm{Su}$ familiar enferma había cometido un intento de suicidio fallido, pocos días después de la muerte de la madre, hecho que provocó el agravamiento de sus enfermedades oncológica y depresiva, causándole la muerte seis meses después. Acerca de ello, la participante manifestó:

"Mi hermana me decía que cuando yo estaba con ella sentía que le levantaba el ánimo porque 
hacíamos afirmaciones de salud, según lo que habíamos aprendido cuando íbamos a las misas y al grupo carismático. Yo le daba y trasmitía energía a mi hermana enferma, mientras una amiga le hacía la técnica de imposición de manos llamada Reiki. Yo hacía oraciones y plegarias y sanación en los chakras para mi hermana internada en el hospital oncológico. Ella me decía - 'cuando venis a verme, me siento bien porque destilás alegría y lo que me hacés de curación en los chakras me hace sentir mejor'. La sanación le hacía sentir menos dolor y más calma, y así pudo morir en paz".

El hombre budista relató que había comenzado su duelo anticipado al recibir el diagnóstico de la enfermedad terminal de su padre a causa de un tumor cerebral inoperable. Al mismo tiempo, enfrentó los cuidados y tratamientos médicos de su madre que padecía graves enfermedades. Acerca de ello manifestó:

"Para mi fue importante hacer plegarias por mi papá durante su enfermedad antes de su fallecimiento. Hacer meditación y Yoga tibetano me ayudaba a sentir vitalidad y a poder seguir adelante .Yo pedía para que mi padre no sufriera, para que tuviera paz y calma mental, que pudiera morir en paz y alcanzara un buen renacimiento luego de su muerte. Pude participar de encuentros con mis hermanos donde tratamos de hallar soluciones a los problemas que teníamos por la internación de mi papá y la enfermedad grave de mi mamá. Algunas situaciones que tenía que resolver me producian enojo, otras angustia y tristeza por el tiempo que me tomaban los trámites que tenia que hacer, y por la desidia en la atención de los servicios médicos. Sentia que nadie se ubicaba en cuál era mi realidad y mis necesidades de ese momento."

Las mujeres metodista y atea atravesaron duelos anticipados de tres años de duración, mientras sus madres estuvieron internadas en institutos geriátricos hasta su fallecimiento. La mujer metodista relató:

"Cuando murió mi mamá, fue tan anunciada y tan esperada su muerte que fue como decir: 'Por fin ya se fue.' Uno no desea la muerte, aunque desea el fin del sufrimiento. Con mi hermana habíamos estado cuidando a mi mamá durante tres años, y nos fuimos despidiendo de ella. Lo más difícil fue el tiempo previo a la muerte cuando mi mamá estaba enferma y tan deteriorada. Pobrecita, había perdido la posibilidad de moverse y dejó de hablar. Me parecía injusto, y me pesaba ir a donde estaba internada porque quedaba muy lejos. Después de su muerte sentí alivio, porque me dolía y no entendía el deterioro que sufría a causa de sus enfermedades."

La mujer atea, quien tuvo a su madre internada en un instituto geriátrico, expresó: "Yo veía a mi madre desvalida y me sentía impotente .Trataba de ver si podía ayudarla a que viviera. El deterioro físico me afectó, ya que es algo real y concreto lo que lleva a un deterioro así. Yo lo sentí con mucha tristeza".

Los sujetos religiosos como los no religiosos que atravesaron un proceso de duelo anticipado reportaron haber sentido estados de angustia, malestar y estrés por ser testigos del deterioro progresivo de la salud de su familiar enfermo, por haber tenido que enfrentar situaciones negativas relacionadas con los cuidados de éste y por las diversas situaciones que tuvieron que afrontar tales como: hospitalización, cuidados intensivos o terminales del ser querido enfermo, o internación de éste en un instituto geriátrico. Todos ellos relataron haber sufrido estrés y desgaste físico y emocional a causa de las tareas de cuidado y del acompañamiento de su familiar. Jaramillo (2001), sostiene que el ser testigo del debilitamiento progresivo del ser querido genera mucho dolor, sensación de vacío y pérdida en los familiares que van constatando cómo va disminuyendo el control y la independencia del ser querido enfermo. La familia debe hacer varios duelos al tener que ir aceptando las pequeñas muertes cotidianas que culminarán en la muerte biológica y total del ser amado.

El sujeto agnóstico pudo anticipar la muerte de su madre, ya que ésta estuvo hospitalizada durante un mes antes de morir. De todos modos, su duelo había comenzado cinco años atrás. Relató cuán importante habia sido atravesar el duelo anticipado, aunque lo vivió con un alto nivel de malestar y angustia. Sobre ello manifestó: 
"Yo iba viendo qué iba pasando de a poco, de a poquito, en pequeñas cuotas. Durante los días en que mi mamá estuvo en terapia intensiva, era tremendo el nivel de estrés; no sólo por la terapia intensiva, sino por lo que yo venía viviendo. Por supuesto que me sirvió ir a verla antes de que se muriera, porque iba viendo qué iba pasando de a poco. Pero al mismo tiempo me dije 'de acá no sale'. Creo que el ver de a poco toda la situación de la enfermedad de mi mamá y poder anticipar su muerte fue muy importante porque fue como pequeños golpecitos que sirvieron para ir preparándome. En los últimos cinco años la venía velando, porque la veía deteriorarse cada vez más y más.."

La mayoría de los participantes que atravesaron un duelo anticipado refirieron que a pesar del dolor que les provocaba el ser testigo del deterioro físico y/o psíquico del familiar enfermo, y de las múltiples situaciones negativas que tuvieron que enfrentar, el poder acompañar y despedirse en forma previa les permitió amortiguar el malestar y les posibilitó una mejor y más rápida aceptación de la muerte y de la pérdida. Lo hallado remite a lo señalado por Jaramillo (2001), en relación a que todo proceso de duelo anticipado permite que los familiares pueden prepararse, anticipar día a día las pérdidas que la enfermedad los obliga a enfrentar, el sufrimiento por el envejecimiento y/o el deterioro del ser querido enfermo y la inminencia de su muerte. Cuando es posible anticipar la pérdida, a pesar de la tristeza que este hecho produce, el conocimiento de la situación posibilita una despedida del familiar y una mejor aceptación de la muerte de éste.

Tanto los sujetos religiosos como los participantes no religiosos que atravesaron duelos anticipados refirieron que sus sentimientos de malestar y estrés habían disminuido a posteriori de la pérdida del ser querido. Quienes atravesaron duelos anticipados de larga duración sintieron una fuerte sobrecarga por estas tareas, por lo que también en estos casos, la muerte fue percibida con alivio, ya que representaba el fin del sufrimiento del ser querido y del propio. Aparece aquí la muerte como algo que pone fin al malestar en quienes atraviesan situaciones de altos niveles de estrés por haber tenido que cuidar a un familiar enfermo (Wortman \& Silver, 2007).
Lo hallado en mi estudio se corresponde con lo señalado por Schultzet al., (2004) acerca de la sensación de alivio que manifiestan sentir los cuidadores de un familiar enfermo, por la sobrecarga de las tareas que deben asumir. También Bonnano (2007), y Wortman y Silver (2007) observan que las personas que han sufrido altos niveles de estrés por tener que cuidar a un familiar enfermo durante un duelo anticipado, a posteriori de la pérdida, suelen experimentar una disminución de los estados negativos, y no un aumento de los mismos.

Asimismo, los sujetos de mi estudio dijeron experimentar sentimientos positivos por haber podido comprobar su capacidad para enfrentar la situación dolorosa, haciendo algo positivo por el ser querido antes de su fallecimiento.

En el caso de los participantes religiosos, éstos sumaron la dimensión espiritual a los cuidados brindados a sus seres queridos enfermos moribundos. Así, refirieron el sentido espiritual de la despedida del ser querido, en términos de desapegarse y dejarlo partir. Resaltaron sus estados mentales, físicos, mentales, emocionales y espirituales de paz, tranquilidad, armonía, equilibrio, claridad y relajación alcanzados a partir de las prácticas religiosas y de los cuidados espirituales brindados a su familiar enfermo y a sí mismos en el duelo anticipado. Destacaron también la ayuda espiritual brindada por pares, clérigos y/o maestros espirituales a sus seres queridos enfermos para que pudieran morir en paz. Conjuntamente, las creencias y prácticas y religiosas espirituales que los sujetos religiosos desarrollaron en el duelo anticipado colaboraron en la disminución del estrés, como también en el logro de estados y sentimientos positivos de éstos. Quienes en el duelo anticipado hicieron uso de los recursos de la religión y la espiritualidad, percibieron una disminución del malestar hacia el final del primer año o en el segundo año de duelo. McIntosh, Silver y Wortman (1993), plantean que las actividades religiosas ayudan tanto en la disminución de la aflicción como en la producción de estados positivos.

Los participantes no religiosos refirieron sus sentimientos de bienestar alcanzados a partir del desarrollo de tareas de cuidado de la enfermedad y/o de la internación de sus familiares, desde su intención 
de ayudarlos a alcanzar una muerte "digna", según su propia cosmovisión no religiosa. Lo hallado en estos casos coincide con la concepción humanista de la muerte y del proceso del morir desarrollada por Kübler-Ross (1991), quien incluye a familiares, amigos y voluntarios para que colaboren en las tareas de acompañamiento de los enfermos moribundos hasta su muerte.

Moskowitz, Folkman y Acree (2003), destacan los estados psicológicos positivos como característicos en quienes atraviesan procesos de duelos anticipados y desarrollan tareas de cuidado de sus seres queridos enfermos, ayudándolos a tener una mejor calidad de vida y a alcanzar una muerte "digna" o en paz. También Bonnano (2007), enfatiza la importancia de las emociones positivas en el duelo anticipado, indicando que las mismas son eficaces para el afrontamiento del intenso malestar: ya que no sólo no impiden un trabajo adecuado de resolución del duelo, sino que juegan un importante papel en la recuperación del deudo. En este sentido, Folkman (2007), afirma que la afectividad positiva tiene un sentido adaptativo en quienes tienen la oportunidad de acompañar y brindar cuidados especiales a sus familiares enfermos moribundos.

En los sujetos religiosos se constató la presencia de relaciones fraternales positivas que colaboraron para la organización y distribución de las tareas de cuidado del ser querido enfermo. El poder dialogar y cooperar con hermanos, demás familiares, amistades y pares religiosos en las tareas de cuidado del familiar enfermo, del otro progenitor vivo y del mantenimiento de la casa familiar los ayudó a disminuir el malestar presente en el duelo anticipado. De igual manera, la reunión o la reconciliación con familiares facilitaron la realización de tareas en conjunto. La colaboración entre hermanos permitió y facilitó encarar y llevar a cabo en forma conjunta las tareas de cuidado y de control de tratamientos médicos presentes en el duelo anticipado, como también la organización de trámites y ritos funerarios. En los dos sujetos no religiosos y en uno de los participantes religiosos, en cambio, se observó que las relaciones conflictivas con sus hermanos y/o hermanas y con otros miembros de su familia agudizaron los problemas propios del duelo anticipado. La falta de apoyo social aumentó el malestar previo y posterior a la pérdida. Por el contrario, los sujetos religiosos que contaron con mayor apoyo social y pudieron distribuir las tareas de cuidado del ser querido enfermo con otros familiares, amigos y pares espirituales mostraron un menor nivel de malestar en el duelo anticipado.

A partir de lo constatado en mi investigación es posible afirmar que los conflictos familiares preexistentes producen efectos negativos en los deudos que no pueden recibir apoyo de sus familiares y/o no pueden interactuar con éstos en forma positiva, todo lo cual conduce al aumento del estrés y del malestar presente en el duelo anticipado. El llevar a cabo tareas en conjunto con familiares dependerá del tipo de vínculo existente entre éstos y quien está próximo a morir. El apoyo de los demás ayuda a disminuir el malestar presente en el duelo anticipado. La calidad de los vínculos podrá o no complicar el tránsito y el desarrollo del duelo anticipado como también del duelo posterior a la muerte del ser querido. En este sentido, será necesario tener en cuenta la existencia objetiva de "otros" y la calidad de las relaciones y el apoyo que esos otros proveen (Yoffe, 2012a).

\section{AFRONTAMIENTO DE PÉRDIDAS INESPE- RADAS, REPENTINAS Y TRÁGICAS}

Los participantes de mi estudio que sufrieron pérdidas repentinas e inesperadas presentaron algunos matices diferenciales: los sujetos judíos no previeron el fallecimiento repentino de sus familiares ancianos y enfermos, por lo que, al recibir la noticia de la muerte se sintieron muy sorprendidos y shoqueados. Aunque la muerte del familiar era esperable debido su estado de vejez y las enfermedades que padecía, en ambos casos, la noticia del fallecimiento los tomó por sorpresa, produciéndoles sensaciones de embotamiento y anestesia emocional. El sujeto judío expresó: "Cuando me comunicaron la muerte de mi papá por teléfono me sentí muy shoqueado por la noticia. Quizás, uno tiene la muerte cerca y aunque mi papá estaba bastante enfermo, pensé que iba a vivir un tiempo más". De todos modos, relató haber sentido alivio al pensar que: "La muerte de mi papá había sido tranquila, sin agonía ni padecimientos dolorosos. Eso era lo que necesitaba para su alma .Yo me quedé tranquilo cuando vi la paz que habia en su rostro después de muerto". También 
la participante judía se refirió a la muerte de su padre muerto de un ataque cardíaco, del siguiente modo:

"La muerte de mi papá era esperada porque los médicos nos habían comunicado que el problema cardíaco que sufría era muy grave, pero aún así me tomó por sorpresa. El tuvo una mejoría una semana antes de morir: se levantaba de la cama y caminaba con euforia; después se fue apagando y a la semana siguiente murió. Me parece fundamental haberme despedido la semana anterior, cuando conversamos de cosas muy íntimas. Eso me dio mucha paz y tranquilidad porque sentí que no quedaron cosas pendientes con él. Así pude recordarlo con una sonrisa como la que tenía ese día cuando hablamos..."

Las sensaciones de shock y anestesia emocional fueron desapareciendo durante la primera semana en la mujer judía, y hacia el final del primer mes de duelo, en el hombre judío, a partir de la participación en rituales funerarios de su credo. Ambos recodaron en sus entrevistas que aunque no habían podido decirle adiós a su familiar enfermo, habían tenido un último encuentro con éste que fue resignificado a posteriori como un tipo de despedida previa, la que colaboró en su proceso de aceptación de la muerte.

A diferencia de ellos, la mujer budista vivió la muerte de su esposo como si hubiera sido una pérdida súbita. Relató en sus entrevistas que su marido había estado internado cinco días en estado de coma inducido después del accidente que sufrió en la vía pública. Durante la hospitalización, mantuvo la ilusión de que su esposo se recuperaría. Afirmó:

"Los días en que mi esposo estaba en terapia intensiva era una situación de mucha irrealidad, porque fue verlo salir de casa y después no lo vi más, ya que no estaba más conciente. Cuando iba al trabajo fue atropellado en la calle. Viví días de pesadilla en la clínica donde estaba internado en estado de coma. Estaba como ausente y yo no podía hablar con él. Hasta la última noche esperaba que se mejorara. Era como una sensación de decir: 'a ver cuándo empieza a hablar, cuándo se revierte todo esto'. Hasta ese momento yo pensé que se iba a recuperar de alguna manera y que se iba a despertar del estado de coma. Su muerte me tomó por sorpresa y el shock me duró mucho tiempo..."

En sus entrevistas, la participante comentó que al no contar con información suficiente y adecuada de parte de médicos y enfermeras, no pudo preparase para la muerte de su marido: "Muchas veces pensé que los médicos sabían que mi esposo no iba a vivir, pero vivió cinco días y ellos no me dijeron nada. Por lo general, los médicos no dicen demasiado, o dicen en algo medio entre líneas, o miran cómo es la persona que va a recibir la noticia y cómo es la situación, y deciden qué es lo mejor para decir en ese momento y si conviene que te digan toda la información o no. Pero a mi no me dijeron nada..."

Dicha participante fue la única que afrontó una pérdida trágica por viudez a causa de una pérdida inesperada y trágica. Al recibir la noticia del fallecimiento de su marido, cayó de la ilusión que tenía de que él se recuperaría. En ese sentido, Jaramillo (2001) señala que la primera reacción ante la noticia de la muerte inesperada de un ser querido suele ser la incredulidad, por lo cual, el deudo podrá sufrir una especie de bloqueo emocional, una anestesia emotiva que funcionará como un mecanismo de defensa cuya función será la de cancelar temporalmente el suceso de la pérdida sufrida, como forma de poder seguir viviendo.

En los tres casos de los participantes religiosos que enfrentaron pérdidas inesperadas, repentinas y/o trágicas se pudo constatar la presencia de sensaciones de shock y de anestesia emocional surgidas al recibir la noticia de la muerte del ser querido. En la mujer budista, el sentirse como si estuviera anestesiada y la sensación de irrealidad surgida al recibir la noticia de la muerte de su marido permanecieron durante más de dos años, mucho más tiempo que en los otros sujetos, ya que la pérdida no sólo fue inesperada, sino también trágica. Parkes (1998), destaca las reacciones de incredulidad y de shock, la retracción social del deudo y las sensaciones de presencia continua del familiar fallecido en quienes sufren una pérdida inesperada y/o repentina. Según el autor, estos estados pueden mantenerse incluso más allá de los dos años, y hasta cuatro años, a posteriori de la pérdida de un ser 
querido. Lo manifestado por la participante acerca de un mayor nivel de malestar y sentimientos negativos más intensos que se mantuvieron más allá del segundo año de duelo, coincide con lo referido por Jaramillo (2001) y Barreto y Sáiz (2007) acerca de las pérdidas por viudez. Asimismo, las pérdidas trágicas suelen hacer sentir a los deudos que la muerte ha irrumpido inesperadamente, y que su vida ha cambiado por completo luego de la pérdida imprevisible del ser amado (Jaramillo, 2001).

En este sentido, los participantes que enfrentaron una muerte repentina pero de un familiar ya anciano y que había estado enfermo previamente, pudieron salir del estado de shock a lo largo del primer mes de duelo. En cambio, en el caso de la pérdida trágica e inesperada sufrido por la mujer budista, las sensaciones de shock y la imposibilidad de creer que la muerte había sucedido fueron de mayor intensidad y persistieron durante mucho más tiempo. Son de resaltar las diferencias entre los duelos por pérdidas inesperadas o repentinas de un familiar anciano y enfermo, donde la muerte es considerada como parte del proceso natural de la vida, y el duelo de quien fallece inesperadamente habiendo gozado de buena salud y siendo aún jóven. Este último tipo de pérdida produce mayor aflicción y malestar que la de quienes, siendo personas de edad mayor, mueren en forma repentina a causa de un ataque cardíaco luego de haber estado enfermos previamente. Las pérdidas inesperadas y trágicas de un familiar adulto sano producen mayores sensaciones de estrés y malestar que las pérdidas repentinas de familiares enfermos y mayores de edad. Stroebe, Stroebe y Hansson (1999), plantean la importancia de tener en cuenta que las pérdidas por muerte súbita o inesperada suelen presentar mayores posibilidades y riesgos de producir efectos negativos en la salud física, mental y emocional de los deudos que las pérdidas anticipadas, por lo cual, los deudos que sufren el primer tipo de pérdidas podrían necesitar contar con apoyo psicoterapéutico en el duelo.

\section{AFRONTAMIENTO DE DUELOS MÚLTIPLES, COMPLICADOS Y PROLONGADOS}

Las participantes judía, budista y católica atravesaron situaciones de duelos múltiples, por haber sufrido dos o más pérdidas consecutivas muy seguidas y cercanas en el tiempo, antes o a posteriori del fallecimiento del ser querido. La mujer católica afrontó la muerte de su hermana seis meses después del fallecimiento de su madre. Sobre ello manifestó: "Sabía que había perdido a mi madre y a mi hermana, pero también sabía que tenía que aceptarlo. Se me caían las lágrimas todo el tiempo. Fui sintiendo que había perdido a mis dos pilares". De todos modos, la participante destacó la importancia de haber podido atravesar un duelo anticipado que le permitió realizar tareas de cuidado de sus familiares enfermos y que le dio la posibilidad de despedirse de ambos.

La mujer judía enfrentó la pérdida repentina de su padre y, dos meses y medio después, la de su suegro, ambos fallecidos de paro cardíaco. Dos años después sufrió la pérdida repentina de una amiga de la infancia, también a causa de un paro cardíaco. A posteriori, se separó y divorció de su marido, luego de un matrimonio de veinticinco años. En sus entrevistas, relató acerca:

"Todavía no me había recuperado de la muerte de mi papá, cuando dos meses y medio después se murió mi suegro de un ataque al corazón. Para mi, fue como revivir el entierro de mi papá. No había tenido tiempo para hacer un duelo, que ya estaba haciendo otro. Como que no tenía respiro, no me terminaba de recuperar de uno, que ya se me habia ido el otro. Sentí que se me abrió la tierra directamente, porque para mí mi padre y mi suegro eran mis dos pilares. Estaba como apaleada porque las dos pérdidas fueron sentidas y muy seguidas. A los dos años, cuando me estaba reponiendo, se murió mi amiga de la infancia de un paro cardiaco. Después de eso me separé, me fui a vivir sola y después me divorcié de mi marido..".

La mujer budista sufrió la pérdida repentina de una amiga de la infancia (por ataque cardíaco) siete meses después del fallecimiento inesperado de su marido. En relación a ello, contó: “A mi me pasaron varias cosas muy feas en mi duelo, ya que bastante poco después de la muerte de mi marido, mi mamá se trató de suicidar. Al mes, se murió de un paro cardiaco mi mejor amiga que tenía mi edad". Un proceso de duelo se puede complicar a partir de la existencia de múltiples pérdidas consecutivas, y prolongarse en el 
tiempo, mucho más allá de lo esperable para un duelo normal.

Las dos participantes religiosas que sufrieron pérdidas inesperadas y sucesivas, y diversas situaciones negativas en sus duelos múltiples refirieron mayores niveles de malestar y estrés, cuya disminución fue lenta y tardía, más allá del final del segundo año de duelo. Jaramillo (2001) plantea que las pérdidas de varias personas de la misma familia en un tiempo acotado implican un tipo de duelo más complejo. En ambos casos, se observó que los sentimientos de extrañar al ser querido fueron en aumento, aunque la realización de procesos de reorganización y el desarrollo de una nueva identidad amortiguaron la aflicción, el malestar y el estrés posterior a las pérdidas sufridas. La intensidad de los sentimientos de extrañar al familiar fallecido disminuyó a medida que lograban recordar a su familiar perdido de manera grata, y podían apreciar su legado y los buenos momentos vividos junto a éste. A partir de esta observación es posible afirmar que los sentimientos negativos pueden disminuir tardíamente; mientras que los sentimientos de extrañar al ser querido pueden incrementarse a lo largo del duelo, aunque sin la misma intensidad que al comienzo de la pérdida.

Son importantes las diferencias detectadas entre quienes atravesaron duelos anticipados y aquellos que sufrieron duelos por pérdidas inesperadas, repentinas o trágicas. La mayoría de los participantes que pudo atravesar un duelo anticipado no presentó sensaciones de shock, anestesia emocional y embotamiento después de la muerte del familiar, ya que su deceso era esperable por la gravedad de las enfermedades que padecían.

En cambio, en los dos sujetos religiosos que enfrentaron duelos complicados por pérdidas sucesivas y múltiples, el proceso se prolongó mucho más allá de los dos años, y el malestar se mantuvo más tiempo que en los demás casos analizados, a pesar de las prácticas religiosas espirituales realizadas por las participantes religiosas (Yoffe, 2012a). Barreto y Sáiz (2007) y Jaramillo (2001), señalan la gravedad, la intensidad y la multiplicidad de los factores que intervienen en los duelos múltiples por pérdidas repentinas y/o inesperadas, trágicas y sucesivas, que son elementos que aumentan la intensidad y duración del estrés y el malestar, incluso más allá del período de dos años, considerado como normal para todo duelo.

\section{COMENTARIOS FINALES}

Cuando es posible anticipar la pérdida de un ser querido, a pesar de la tristeza que este hecho produce, el conocimiento de la situación posibilitará una mayor aceptación de la muerte del familiar. Sin embargo, aún cuando la anticipación provee de algunos aspectos positivos para el posterior ajuste emocional, en los duelos anticipados suele haber presencia de altos niveles de malestar y estrés debido a las diversas situaciones que se tienen que afrontar como: la hospitalización, los cuidados intensivos o terminales del ser querido enfermo, la internación de éste en un instituto geriátrico, el ser testigo del deterioro y/ o de la enfermedad del familiar, entre otros aspectos (Jaramillo, 2001).

Cabe destacar los estados psicológicos positivos señalados como característicos en quienes atraviesan procesos de duelos anticipados y desarrollan tareas de cuidado de sus seres queridos enfermos, ayudándolos a tener una mejor calidad de vida y a alcanzar una muerte "digna" o en paz. La afectividad positiva tiene un sentido adaptativo en quienes siendo o no religiosos, tienen la oportunidad de acompañar y brindar cuidados especiales a sus familiares enfermos moribundos (Moskowitz, Folkman \& Acree, 2003).

En los duelos anticipados como en las pérdidas inesperadas o repentinas de un familiar anciano y enfermo, la muerte es considerada como parte del proceso natural de la vida. Las personas que enfrentan tales tipos de pérdida de un familiar anciano y enfermo previamente suelen sentirse shoqueadas por lo repentino del fallecimiento, pero logran salir del estado de shock más rápidamente que quienes afrontan la pérdida inesperada y trágica de un familiar adulto sano (Yoffe, 2012a). La no predictibilidad y la inminencia de la pérdida se suman como factores críticos a la intensidad y prolongación del estrés, a un hecho que contradice la lógica de la cronología de los eventos en relación al ciclo vital, como es el caso de la muerte de alguien joven (Lazarus \& Folkman, 1984). En cambio, los duelos de quienes fallecen en forma inesperada, repentina y/o trágica habiendo gozado de 
buena salud y siendo aún jóvenes son más difíciles de afrontar, y los deudos suelen necesitar más tiempo para aceptar tal tipo de pérdida. La gravedad, la intensidad y la multiplicidad de los factores que intervienen en los duelos por pérdidas repentinas, inesperadas, trágicas y/o sucesivas son elementos que pueden aumentar la intensidad y duración del estrés y el malestar de los deudos, incluso más allá del período de dos años, considerado como normal para todo duelo (Jaramillo, 2001; Barreto \& Sáiz, 2007).

\section{REFERENCIAS}

Attig,T. (2007).Relearning the world: Making and finding meanings. En Neimeyer, R.A. (Ed.) Meaning Reconstruction and the Experience of Loss. Washington DC: American Psychological Association, 33-54.

Balk, D. (1991). Sibbling death, adolescent bereavement, and religion. Death Studies, 15, 120.

Barreto, M.P., \& Sáiz, C.(2007). Muerte y duelo. Madrid: Síntesis.

Bolwby, J. (1980). La pérdida afectiva. Tristeza y depresión. Buenos Aires: Paidós.

Bolwby, J.(1998). El apego. Buenos Aires: Paidós.

Bonanno,G.A.(2007).Grief and Emotion: A Social Functional Perspective. En Stroebe, M., Hansson, R., Stroebe, W.,\& Schut, H.(Eds.). Handbook of Bereavement Research: Consequences, Coping and Care. Washington, DC: American Psychological Association, 493-516.

Campos, M., Páez, D., \& Velasco, C. (2004). Afrontamiento y regulación emocional de hechos traumáticos: un estudio longitudinal sobre el 11M. En Ansiedad y Estrés, 10 (2-3),277-286.

Campos, M., Páez, D.,Fernández-Berrocal, P., Igartúa, J.J.,Méndez,D.,Moscoso,S., Palomero, C., Pérez, J.A., Rodríguez, M., Salgado-Velo, \& Tasado, J. (2004). Las actividades religiosas como formas de afrontamiento de hechos estresantes y traumáticos con referencia a las manifestaciones del $11-\mathrm{M}$. Ansiedad y Estrés, 10 (2-3), 1-11.
Center for the Advancement of Health. (2003). Report on Bereavement and Grief Research. November 2003. Washington, DC: Center for the Advancement of Health.

Christakisa, N.A, Iwashyna,T.J. (2003) The health impact of health care on families: a matched cohort study of hospice use by decedents and mortality outcomes in surviving, widowed spouses. Social Science \& Medicine 57 (2003), 465-475.

Dubertein, P. (2000).Death cannot keep us apart: mortality following bereavement. En Duberstein, PR \& Masling JM (Eds). Psychodynamic perspectives on sickness and health.Washington, DC: American Psychological Association, 259331.

Fernández, I., Ubillos, S., Zubieta, E., \& Páez, D. (2001). Cuadernos de Práctica de Psicología Social de la Salud. Facultad de Psicología, Universidad del País Vasco.

Folkman, S. (1997). Positive psychological states and coping with severe stress. Social Science and Medicine,45, 1207-1221.

Folkman, S.(2007). Revised Coping Theory and the process of Bereavement. En Stroebe, M.S., Stroebe, W., Hansson, R.O. \& Schut, H. (Eds). (2007). Handbook of Bereavement Research Consecuences, Coping and Care. Washington: American Psychological Association, 563-583.

Fitzpatrick,T.(1998). Bereavement events among elderly men: the effects of stress and health. Journal of Applied Gerontology, 17 (2).

Freud, S. (1917). Duelo y melancolia.Obras Completas. Tomo XIV. Buenos Aires: Amorrortu. (1993).

Glick, I., Weiss, R. S., \& Parkes, C. M. (1974). The first year of bereavement. New York: Wiley Interscience.

Goodkin, K., Baldewicz, T. \& Blaney, N. T. (2007) Physiological Effects of Bereavement and Beravement Support Group Interventions. En Stroebe, M., Hansson, R. O., Stroebe, W. \& Schut, H. (Eds.) Handbook of Bereavement Research: Consequences, Coping and Care. Washington, American Psychological Association, 671-704. 
Jacobs, S. (1999). Traumatic grief: diagnosis, treatment, and prevention. Psychology Press. Philadelphia: Brunner-Mazel.

Janoff-Bulman, R. (1992). Shattered assumptions: Towards a new pshcology of trauma. New York: The Free Press.

Jones, D.R., \& Goldblatt, P.O. (1987). Cause of Death in Widow(ers) and Spouses. Journal of Biosocial Science, 19: 107-21.

Hagman,G .(1995). Death of a self object: Toward a self psychology of the mourning process. En Goldberg,A. (Ed.), Progress in self psychology, Vol. 11. Hillsdale, NJ: Analytic Press, 189-205.

Keltner, D.,\& Bonanno, G.A. (1997). A study of laughter and dissociation: Distintc correlates of laughter and smiling during bereavement. Journal of Personality and Social Psychology, 73, 687702.

Kübler-Ross, E. (1969). On death and Dying. New York: Mac-Millan Publications.

Kübler-Ross, E. (1991). On life after death. Berkeley, CA. : Celestial Arts.

Kübler-Ross, E., \& Kessler, D. (2005). On Grief and Grieving. Finding the meaning of grief through the five stages of loss. New York: Scribner.

Lazarus, R.S., \& Folkman, S. (1984). Stress, Appraisal, and Coping. New York: Springer Publishing Company.

Levy, A. (1999). The orphaned adult. Understanding and coping with grief and change after the death of our parents. Massachusetts: Perseus Books.

Lindemann, E. (1994). The symptomatology and management of acute grief. American Journal of Psychiatry 101, 141-148.

Lund, D.A. (1989). Conclusions about bereavement in later life and implications for interventions for future research. En Lund, D.A.(Ed).Older bereaved spouses: Research with practical applications. New York: Hemisphere, 217-231.

Lundin, T. (1984). Mortality following bereavement. British Journal of Psychiatry, 144, 84-88.

Martinson, I. M., \& Campos, R. G. (1991). Adolescent bereavement: Long -term responses to a sibling's death from cancer. Journal of Adolescent Research, 6, 54-69.

McIntosh, D.N., Silver, R.C., \& Wortman, C.B. (1993). Religion's role in adjustment to a negative life event: Coping with the loss of a child. Journal of Personality and Social Psychology, Vol 65(4), Oct 1993, 812-821.

Mellstrom, D., Nilsson A., Oden, A., Rundgren, A. \& Svanborg, A. (1982). Mortality among the widowed in Sweden. Scandinavian Journal of Social Medicine, 10: 33-41.

Moskowitz, J. T., Folkman, S., \& Acree, M. (2003). Do positive psychological states shed light on recovery from bereavement? Findings from a 3-year longitudinal study. Death Studies, 27, 471-500.

Neimeyer, R.A. (Ed). (2001). Meaning reconstruction and the experience of loss. Washington, DC: American Psychological Association.

Neimeyer, R.A. (2007). Aprender de la pérdida. Una guía para afrontar el duelo. Barcelona: Paidós.

Osterweis, M., Solomon, F \& Green, M.(Eds) (1984). Comittee for the Study of Health Consequences of the Stress of Bereavement,Institute of Medicine. Bereavement: reactions,consequences, and care. Washington, DC: National Academy Press.

Páez, D., Basabe, N., Ubillos, S., \& González-Castro, J.L.(2007). Social sharing, participation in demonstrations, emotional climate, and coping with collective violence after the march 11th Madrid bombings. Journal of Social Issues, 63(2), 323-337.

Páez, D., Bilbao, M., \& Javaloy, F. (2008). Del trauma a la felicidad. Los hechos negativos pueden generar creencias positivas y crecimiento. En Casullo, M.M.(comp).Prácticas de Psicología Positiva. Buenos Aires: Lugar Editorial, 159-202.

Pargament, K. I. (1997). Psychology of Religion and Coping. Theory, research and practice. New York-London: The Guilford Press.

Parkes, C. M, (1972). Bereavement: Studies of grief in adult life. London: Tavistock.

Parkes, C. M. (1998). Bereavement. Studies of grief in adult life. Madison, CT: International Universities Press. 
Parkes, C.M. (2001). Bereavement. studies of grief in adult life. Philadelpia: International Universities Press.

Parkes, C.M., \& Markus, A. (eds). (1998). Coping with Loss: Helping patients and their families. London: BMJ Publishing Group.

Parkes, C., Laungani, P.,\& Young, B.(Eds). (2000). Death and Bereavement across cultures. London -New York: Routlegde.

Parkes, C.M., \& Weiss, R.S. (1983). Recovery from Bereavement. New York: Basic Books.

Pennebaker, J.W. (1997). Writing about emotional experiences as a therapeutic process. Psychological Science, 8, 162-166.

Prigerson, H.G. \& Jacobs, S. C. (2001). Traumatic grief as a distinct disorder: A rationale, consensus criteria, and a preliminary empirical test. En Stroebe, M.S, Hansson, R.O, Stroebe, W \& Schut, H. (Eds.). Handbook of bereavement research: Consequences, coping, and care. Washington, DC: American Psychological Association, 613-637.

Rando,T. (1984). Grief, dying, and death: Clinical interventions for caregivers. Champaign, IL: Research Press.

Rando, T. (1991). How to go on living when someone you love dies. New York: Bantam.

Rosenblatt P.C., Walsh, R.P., \& Jackson, D.A. (1976). Grief and mourning in cross/cultural perspective. New Haven, CT: Human Relations Area Files Press.

Rosenblatt, P.C. (2000). Grief in small scale societies. En Parkes, C.M., Laungani, P, \& Young, B.(Eds.). Death and bereavement across cultures. London: London- Routlegde , 27-51.

Rosemblatt, P. (2007). A Social Constructionist Perspective on Cultural Differences in Grief. En Stroebe,M., Hansson, R., Stroebe,W., \&Schut, H.(Eds.). Handbook of Bereavement Research: Consequences, Coping and Care. Washington, DC:American Psychological Association, 285300 .

Schulz, R., Boerner, K. \& Horowitz, A. (2004). Positive Aspects of Caregiving and Adaptation to
Bereavement. Psychology and Aging, American Psychological Association 2004, Vol. 19, No. 4, 668-675.

Schupp, L. (2007). Grief. Normal, Complicated, Traumatic. Wisconsin: Pesi Ed.

Stylianos, S., \&Vachon, M. (1999). The role of social support in bereavement. En Stroebe, M.S., Stroebe, W., \& Hansson,R.O.(Eds) Handbook of Bereavement: Theory, Research and Intervention. London \& New York: Cambridge University Press, 397-410.

Stroebe,W., \& Stroebe, M.S. (1987). Bereavement and health. New York: Cambridge University Press.

Stroebe,W., \& Stroebe, M.S. (1993). The mortality of bereavement. En Stroebe, M.S., Stroebe ,W.,\& Hansson,R.O.(Eds). Handbook of Bereavement: Theory, research, and intervention. Cambridge, England. Cambridge University Press, 208-226.

Stroebe, W., \& Stroebe, M. (1994). Bereavement and Health. The psychological and physical consequences of partner loss. New York: Cambridge University Press.

Stroebe, M., Stroebe, W., \& Hansson, R. (1999). Handbook of Bereavement: Theory, Research and Intervention. London - New York: Cambridge University Press.

Stroebe, M., Stroebe, W., \& Hansson, R. (1999). Contemporary Themes and Controversies in Bereavement Research. En Handbook of Bereavement. Theory, Research and Intervention. London - New York: Cambridge University Press, 457-475.

Stroebe, M.S., \& Schut, H.(2007). Models of Coping with Bereavement. En Stroebe, M., Hansson,R., Stroebe,W., \& Schut, H. (Eds.). Handbook of BereavementResearch:Consequences,Coping and Care. Washington, DC:American Psychological Association, 375-404.

Stroebe, M., Hansson, R., Stroebe, W., \& Schut, H. (2007). Future Directions for Bereavement Research. En Stroebe, M., Hansson, R., Stroebe, W., \& Schut, H. (Eds.). Handbook of Bereavement Research: Consequences, Coping and Care. Washington, DC: American Psychological Association, 741-766. 
Stroebe, M., Hansson, R., Stroebe, W., \& Schut, H. (Eds.) (2007). Handbook of Bereavement Research: Consequences, Coping and Care. Washington, DC: American Psychological Association.

Tarockova, T (1996). Grief Counseling as an Emerging Sphere of Psychological. Counseling. Child and Adolescent. Social Work Journal, 13 (1):3-21. 1997 (21) .

Tedeschi, R. G, \& Calhoun, L. G. (1995). Trauma and transformation: Growing in the aftermath of suffering. Thousand Oaks, CA:Sage.

Weiss, R. (1999).Loss and recovery. En Stroebe,M., S troebe,W.,Hansson,R.(Eds).(1999). Handbook of Bereavement: Theory, research and Interevention. London -New York: Cambridge University Press, 271-284.

Worden, J. W. (1997). El tratamiento del duelo: asesoramiento psicológico y terapia. Buenos Aires: Paidós.

Wortman, C. \& Silver, R. C. (1992). Reconsidering assumptions about coping with loss: An overview of current research. In Filip,S.H., Montada,L. \& Lerner, M. (Eds), Life crises and experiences of loss in adulthood. Hillsdale, NJ: Erlbaum, 341365 .
Wortman,C.\&Silver,R.C.(2007).The Myths of Coping with Loss Revisited. En Stroebe, Hansson,Stroebe, \& Schut, H. (Eds). (2007). Handbook of Bereavement Research: Consequences, Coping and Care, 405-430.Washington, DC: American Psychological Association.

Yoffe, L. (2012a). La influencia de las creencias $y$ prácticas religiosas espirituales en el afrontamiento de la pérdida por muerte de un ser querido. Tesis doctoral no publicada. Universidad de Palermo, Buenos Aires, Argentina.

Yoffe, L. (2012c).La religión y la espiritualidad en los duelos: desde la visión de la psicología positiva. En: Alarcón, R.A.(Dir.). Psicología Positiva. Lima: Facultad de Psicología y Humanidades, Universidad Femenina del Sagrado Corazón, 83116.

Yoffe, L. (2012d). Cambios y crecimiento personal a partir del duelo: una mirada desde la psicologia positiva. En: Alarcón, R.A.(Dir.). Psicología Positiva. Lima: Facultad de Psicología y Humanidades, Universidad Femenina del Sagrado Corazón, 33-165.
Fecha de recepción: 1 de junio de 2013

Fecha de aceptación: 24 de septiembre de 2013 